\title{
Electric Sector Capacity Planning under Uncertainty: Climate Policy and Natural Gas in the US
}

\author{
John E. Bistline* \\ ${ }^{a}$ Electric Power Research Institute, 3420 Hillview Ave, Palo Alto, CA 94304, USA \\ ${ }^{b}$ Steyer-Taylor Center for Energy Policy and Finance, Stanford University
}

\begin{abstract}
This research investigates the dynamics of capacity planning and dispatch in the US electric power sector under a range of technological, economic, and policy-related uncertainties. Using a two-stage stochastic programming approach, model results suggest that the two most critical risks in the nearterm planning process of the uncertainties considered here are natural gas prices and the stringency of climate policy. Stochastic strategies indicate that some near-term hedging from lower-cost wind and nuclear may occur but robustly demonstrate that delaying investment and waiting for more information can be optimal to avoid stranding capital-intensive assets. Hedging strategies protect against downside losses while retaining the option value of deferring irreversible commitments until more information is available about potentially lucrative market opportunities. These results are explained in terms of the optionality of investments in the electric power sector, leading to more general insights about uncertainty, learning, and irreversibility. The stochastic solution is especially valuable if decision-makers do not sufficiently account for the potential of climate constraints in future decades or if fuel price projections are outdated.
\end{abstract}

Keywords: Electricity, uncertainty, stochastic programming, climate policy, risk management

JEL: L94, Q48, Q52, D84

\footnotetext{
*Tel.: +1 6503538566 .

Email address: jbistline@epri.com (John E. Bistline)
} 


\section{Introduction}

Utilities, generators, and other energy planners face many uncertainties when making near-term decisions. Since energy-sector assets like power plants, transmission facilities, and refineries are long-lived and largely irreversible, insufficiently characterizing or accounting for uncertainty can impose economic and environmental burdens on a range of stakeholders. Decisionmakers in the US electric power sector must grapple with many simultaneous challenges, including compliance with an array of environmental regulations, an aging fleet of generators, sudden changes to the economics of fossil resources, and an increased emphasis on demand-side management.

Given the complexity and centrality of uncertainty in energy and environmental management, there is a need for decision support tools to provide a greater sense of clarity and to reduce exposure to downside losses while preserving options for upside gains from volatility. However, in the energy modeling community, there is currently a gap between the recognition of uncertainty's importance and its actual incorporation in models. Many energy models use deterministic frameworks, and when uncertainty analysis is performed, it often involves simple methods like sensitivity or scenario analysis (Kann and Weyant, 2000). When incorporating uncertainty, modelers typically opt for propagation approaches like Monte Carlo analysis. Since propagation frameworks suggest a different strategy for each state of the world, these approaches leave decision-makers in a quandary about how to choose among alternatives before uncertainty is resolved and how to translate results of modeling efforts into actionable insights (Birge and Louveaux, 2011; Infanger, 1994). Additionally, since the costs associated with uncertainty remain unknown, propagation frameworks cannot quantify the relative importance of uncertainties.

In contrast, sequential decision-making frameworks like stochastic programming and stochastic control incorporate uncertainty explicitly and identify hedging strategies that balance the risks of premature action with those

of delay. Such models determine optimal policies in multiple stages based on updated information and offer more robust treatments of uncertainty than propagation models, which select policies once and do not incorporate learning thereafter. The energy modeling literature that uses stochastic programming typically has limited capabilities and does not take full advantage of the framework (Bistline and Weyant, 2013). Appendix A discusses this literature in detail. 
This work investigates how the explicit inclusion of uncertainty through sequential decision-making can provide insights to energy planners. The objective is to identify novel conclusions that cannot be captured in (or would not be apparent using) standard deterministic approaches (Birge and Rosa, 1996; Kanudia and Shukla, 1998; Durand-Lasserve et al., 2010; Usher and Strachan, 2012). In doing so, the tools developed and applied here provide better guidance for uncertainty characterization, analysis, and communication. In particular, this paper investigates how uncertainty may impact the deployment of supply-side technologies in the US power sector using a twostage stochastic programming framework with uncertainties related to the stringency of climate policy, natural gas prices, upstream methane emissions from gas production, and others.

The motivations of this research are to examine how technological, economic, and policy-related uncertainties can impact near-term planning decisions and to quantify the value of explicitly incorporating uncertainty and flexibility in the decision-making process. In addition to providing a framework for analyzing adaptive management strategies, this energy-economic model is among the first to use a stochastic programming framework with a wide range of simultaneous uncertainties and many scenarios. The model is also the first to incorporate upstream emissions from natural gas production to examine the trade-offs between uncertain life-cycle costs and environmental impacts of different technologies, as discussed in Section 3. Another contribution is to offer rigorous quantifications of distributions for uncertainties instead of using ad-hoc probabilities or uniform distributions. This characteristic exhibits a higher degree of fidelity to the real-world investment problems of utilities and generators.

The remainder of the paper is organized as follows. Section 2 formulates a two-stage stochastic programming model of capacity planning for the US power sector and defines metrics for quantifying the importance of uncertainty. Section 3 discusses the uncertainties included in the analysis and their quantification. Section 4 presents model results for capacity planning and dispatch under these uncertainties, and Section 5 analyzes these results in the broader context of learning, irreversibility, and optionality of capital investments. Section 6 summarizes the primary insights from the analysis. 


\section{Modeling Approach}

Capacity planning in the power sector is well-suited to the stochastic programming paradigm, where strategies adjust over time as new information becomes available about technologies, resources, and polices. Decisions about capacity expansion and operation take place against long and highly uncertain planning horizons. Uncertainties about developments in the system environment impact the cost-effectiveness of planning decisions, particularly in the power sector where long-lived and irreversible capital investments are designed to last many decades. The long lead times and lifetimes of assets mean that the environments in which power plants come online may be very different from the ones in which they are planned. Hence, suboptimal near-term decisions that do not account for a range of potential fuel prices and environmental policies (for example) can cost ratepayers, investors, and taxpayers and have important economic and environmental implications.

\subsection{Deterministic Capacity Planning Model}

This section discusses the development of an intertemporal optimization model of capacity planning and dispatch in the US electric power sector to address the research questions from Section $1 .{ }^{1}$ The discrete-time model determines capacity investment and production decisions between 2010 and 2050 in five-year increments with three load segments per year. The segments create a piecewise approximation of the load duration curve and preserve total annual generation and peak-load characteristics. The model uses a partial equilibrium framework with exogenous fuel prices. Data for the model come from a variety of public sources, as described in Appendix B.

The model assumes that capacity installation and electricity production decisions are coordinated among utilities and generators. In the core deterministic model, utilities determine the path of investment and capital stock that minimizes the sum of discounted energy system costs for all capacity blocks during all periods while satisfying power system constraints. Appendix B and Bistline (2013) provide additional mathematical detail about the model.

\footnotetext{
${ }^{1}$ The model data and code are available online.
} 


\subsection{Two-Stage Stochastic Programming Model with Recourse}

The linear programming model in Section 2.1 computes the optimal investment strategies for the deterministic capacity planning problem. Under perfect information, this solution provides a lower bound on discounted costs in a particular scenario. Due to the difficulties of predicting the outcomes of uncertainties introduced in Section 3, it is unrealistic to assume that a strategy that is optimized for a given scenario will be optimal under a range of states of the world. Disregarding inherently random characteristics may limit the usefulness of solutions designed using deterministic approaches.

Stochastic programming techniques can be used to compute optimal hedging strategies in problems with uncertain data, which provide contingency plans that adapt to realizations of random variables (Beale, 1955; Dantzig, 1955). These solutions perform reasonably well under a variety of plausible scenarios. Based on the notation of Infanger (1994), the basic two-stage stochastic program with recourse in a cost-minimization setting can be formulated as:

$$
\begin{aligned}
& \min z=c^{T} x+\mathbb{E}_{\omega} f^{\omega} y^{\omega} \\
& \text { s.t. } A x=b \\
& -B^{\omega} x+\quad D^{\omega} y^{\omega}=d^{\omega} \\
& x, \quad y^{\omega} \geq 0, \omega \in \Omega
\end{aligned}
$$

$\Omega \quad$ set of all outcome paths

$\omega \in \Omega$ state of the world

$x \quad$ vector of first-stage decisions

$y \quad$ vector of second-stage (recourse) decisions

Here, all values corresponding to objective function coefficients (the $c$ vector) and first-stage constraints (the $A$ matrix and $b$ vector) are known with certainty. The second-stage objective coefficients (the $f^{\omega}$ vector) and constraint parameters (the $B^{\omega}$ and $D^{\omega}$ matrices and $d^{\omega}$ vector) are unknown when utilities make first-stage decisions and are characterized only by discrete probability distributions.

Two important questions for decision-makers and modelers are: How much should decision-makers be willing to pay for information about uncertain quantities? What is the value of incorporating uncertainty explicitly in the decision-making process instead of using a deterministic approximation? 
Stochastic programming settings provide convenient mathematical frameworks and metrics for quantifying answers to these questions.

Before discussing these measures, it is useful to distinguish between three approaches for solving problems under uncertainty (Infanger, 1994). The wait-and-see (learn-then-act) approach assumes that uncertainty is resolved and the outcome $\omega \in \Omega$ can be observed before selecting the decision vector $x$ (Madansky, 1960). This solution suggests that perfect information is available before decisions are made. The problem can be formulated as:

$$
\begin{aligned}
& z^{\omega}=\min f(x, \omega) \\
& \text { s.t. } x \in C^{\omega} \subseteq \mathbb{R}^{n}
\end{aligned}
$$

where the wait-and-see solution is $x^{\omega} \in \operatorname{argmin}\left\{f(x, \omega) \mid x \in C^{\omega}\right\}$. The expected cost with perfect information can be found by taking the expected value over all possible scenarios: $z_{w s}=\mathbb{E} z^{\omega}=\sum_{\omega \in \Omega} z^{\omega} p(\omega)$. The problem with this approach is that the resulting solutions are not implementable, which means that outcomes are superoptimal and decisions cannot be regretted ex post.

The here-and-now approach finds a solution $x^{*}$ that hedges against all enumerated contingencies. The optimal stochastic solution addresses the problem where a decision-maker cannot completely resolve uncertainty before acting:

$$
\begin{aligned}
& z^{*}=\min \mathbb{E}_{\omega} f(x, \omega) \\
& \text { s.t. } x \in C=\bigcap_{\omega \in \Omega} C^{\omega}
\end{aligned}
$$

where the here-and-now solution is expressed as $x^{*} \in \operatorname{argmin}\left\{\mathbb{E}_{\omega} f(x, \omega) \mid x \in\right.$ $\left.\cap C^{\omega}\right\}$. The expected cost of the stochastic solution is $z^{*}=\min _{x} \mathbb{E}_{\omega} f(x, \omega)$.

Finally, the expected-value approach replaces the stochastic parameters by their expected values or another measure of central tendency. This approach sidesteps uncertainty by using a single set of input parameters and solves the 
resulting deterministic problem:

$$
\begin{array}{r}
\hat{z}_{d}=\min f(x, \bar{\omega}) \\
\text { s.t. } x \in C^{\bar{\omega}}
\end{array}
$$

where $\bar{\omega}=\mathbb{E} \omega=\sum_{\omega \in \Omega} \omega p(\omega)$, and the expected-value solution is $x_{d} \in$ $\operatorname{argmin}\left\{f(x, \bar{\omega}) \mid x \in C^{\bar{\omega}}\right\}$. The expected cost of the expected-value solution is $z_{d}=\mathbb{E}_{\omega} f\left(x_{d}, \omega\right)$. Although this approach is comparatively straightforward to formulate and solve, this simplification may exclude critical dynamics of the uncertain system and perform poorly in expectation. The expectedvalue approach initially solves the deterministic optimization problem where uncertain parameters are replaced by their mean values. Then, first-stage decision variables are fixed to this solution, and the second-stage problem is solved for each possible state of the world.

Figure 1 compares the expected costs of the expected-value $\left(z_{d}\right)$, stochastic $\left(z^{*}\right)$, and perfect information $\left(z_{w s}\right)$ strategies. $^{2}$ The figure also illustrates the metrics discussed in Section 2.3.

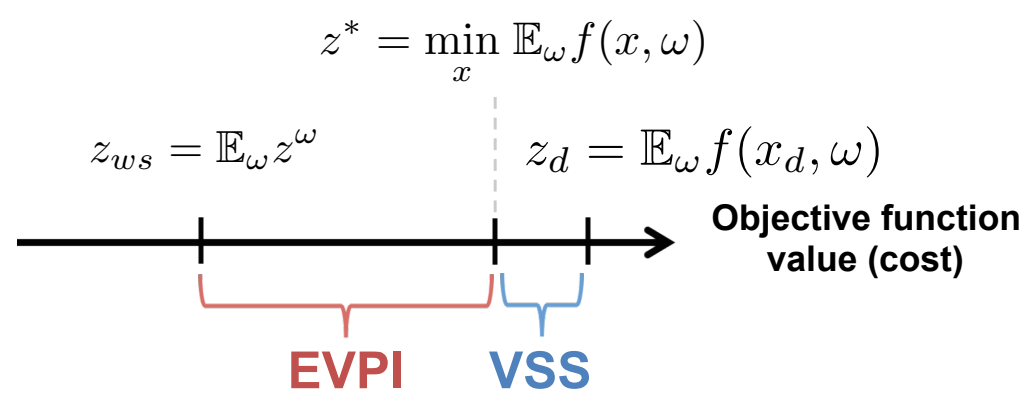

Figure 1: Number line comparing expected costs under different decision-making approaches. The spacing between values is illustrative.

\subsection{Metrics}

The importance of uncertainties is assessed through two metrics: the expected value of perfect information (EVPI) and value of the stochastic solution (VSS). Of the limited energy modeling research that uses a stochastic

\footnotetext{
${ }^{2}$ Madansky (1960) proves that $\hat{z}_{d} \leq z_{w s} \leq z^{*} \leq z_{d}$ using Jensen's inequality and the convexity of the objective function.
} 
programming framework, few studies perform EVPI calculations and even fewer incorporate VSS metrics, as discussed in Appendix A. The underutilization of these metrics neglects important opportunities for policy insight and model development afforded by stochastic programming (Bistline and Weyant, 2013).

The EVPI compares the expected costs of the stochastic and wait-andsee solutions and represents the expected change in the objective function value if perfectly accurate forecasts are available. The EVPI has important implications for decision-makers in placing a bound on their willingness to pay for information-gathering activities. The metric is defined as:

$$
\begin{aligned}
\mathrm{EVPI} & \equiv z^{*}-z_{w s} \\
& =\min _{x} \mathbb{E}_{\omega} f(x, \omega)-\mathbb{E}_{\omega}\left[\min _{x} f(x, \omega)\right]
\end{aligned}
$$

The EVPI captures the notion that, even though parameters may contribute to variations in the objective function value, these uncertainties may be irrelevant to decisions. This feature allows stochastic programming models to identify decision-relevant parameters, which is one of the limitations of deterministic sensitivity analyses and uncertainty propagation approaches.

Despite the usefulness of this metric, there are a few complicating factors involved in calculating the EVPI. First, synergistic effects among contemporaneous uncertainties mean that the joint value of information likely differs from the sum of individual ones. Such effects are important areas of exploration but require frameworks capable of modeling many simultaneous scenarios like the one discussed here. Second, it is often challenging to identify a decision-maker who would place a value on information or to pinpoint appropriate sources of information. In some cases, uncertainty may be irreducible, even though the EVPI is large. Third, although one hopes that gathering more information will reduce uncertainty, research and exploration often reveal unforeseen complexities and temporarily can increase uncertainty (Hannart et al., 2013; Morgan and Keith, 1995). Finally, since the EVPI depends on prior information about an uncertain parameter, the EVPI can be sensitive to tail probabilities. If the well-established overconfidence effect narrows prior distributions ${ }^{3}$ the EVPI is likely biased downward,

\footnotetext{
${ }^{3}$ The overconfidence effect refers to the systematic tendency to underestimate uncertainty so that a decision-maker's subjective confidence in their probability assessments is
} 
which may lead decision-makers to systematically underestimate the utility of information gathering (Hammitt and Shlyakhter, 1999).

The VSS compares the expected costs of the expected-value and stochastic solutions and describes the "value of knowing how little you know" (Morgan and Henrion, 1990). It quantifies the expected difference in cost for a decision based on stochastic analysis and one that ignores uncertainty by using a deterministic solution. The VSS is defined by the equation:

$$
\begin{aligned}
\mathrm{VSS} & \equiv z_{d}-z^{*} \\
& =\mathbb{E}_{\omega} f\left(x_{d}, \omega\right)-\min _{x} \mathbb{E}_{\omega} f(x, \omega)
\end{aligned}
$$

The explicit inclusion of uncertainty makes decision-makers at least no worse off in expectation, assuming that the additional costs of analysis and interpretation are reasonably small. The VSS is largest in contexts with asymmetrical payoffs for miscalculations and misforecasts.

The VSS has many implications for decision-makers and modelers. Since stochastic programs are more difficult to formulate and solve than deterministic models, the VSS can indicate whether approximations of optimal strategies are nearly optimal or extremely suboptimal. Hence, decision-makers can use the VSS as a means to gauge the quality of an approximate solution and to quantify the value of incorporating uncertainty explicitly. The VSS calculates the added value of using a sequential decision-making model and guides analysts in the process of model construction by identifying the most important uncertainties for inclusion. The VSS also can be used to prioritize efforts to quantify various uncertainties by offering general guidance for tasks like allocating resources to assess distributions, selecting the extent and exhaustiveness of elicitation efforts, and determining computational trade-offs when discretizing distributions.

Initially, it appears contradictory that the VSS can be used to determine whether a stochastic framework is appropriate, since calculating the VSS seems to assume that a probabilistic model is already available. However, upper bounds for VSS values can be approximated using a core deterministic model. Birge (1982) shows how the EVPI and VSS are bounded by $z_{d}-z_{w s}$. The quantities needed to calculate this bound can be computed using standard deterministic models but require at least preliminary esti-

higher than their objective accuracy (Fischhoff et al., 1977). 
mates of probabilities associated with different scenarios, which underscores the importance of uncertainty quantification.

Even if a stochastic model is available, the VSS is still useful for model development. The VSS for each uncertainty under consideration can be calculated individually to determine which random parameters have the largest VSS magnitudes. Such values indicate that these uncertainties should be included in more computationally complex joint model runs and should be given additional attention during the uncertainty quantification and model refinement processes.

The EVPI and VSS are different metrics that compare the expected value of the stochastic solution with another made without incorporating uncertainty. For the VSS, the other decision is made when uncertainty is disregarded, even though it still exists. For the EVPI, the other decision is made when uncertainty is removed by obtaining perfect information. Thus, the VSS can be viewed as the additional expected cost of pretending that uncertainty does not exist, whereas the EVPI is the expected cost of being uncertain (Morgan and Henrion, 1990).

\section{Uncertainties Considered in the Analysis}

For this analysis, the model simultaneously represents eight parameters as random variables. This section describes the motivations for including these random variables and how uncertainty is characterized using approaches like expert elicitations and econometric modeling.

\subsection{Climate Policy}

There are many sources of uncertainty that will determine the stringency of policy measures to curb greenhouse emissions in the US and elsewhere. The portfolio composition of generating assets will be influenced by firms' expectations about the timing, form, breadth, and stringency of future policies.

This analysis assumes that the policy will take the form of a price on equivalent greenhouse gas emissions, which is uncertain until the second stage. ${ }^{4}$ After this period, the $\mathrm{CO}_{2}$ price is assumed to escalate in real terms at a constant rate. Data to parameterize the distribution come from a sample of

\footnotetext{
${ }^{4}$ The only greenhouse gases incorporated in the model are $\mathrm{CO}_{2}$ and $\mathrm{CH}_{4}$.
} 
14 Western utility integrated resource plans (IRPs), which make assumptions about the trajectory of carbon taxes over multidecadal planning periods. ${ }^{5}$ All 14 utilities in this sample assume that the climate policy will come in the form of a tax. Given how many of these utilities are located in the Western Electricity Coordinating Council, which may introduce a selection bias, Bistline (2014b) explores the sensitivity of this model to an alternate distribution for the climate policy uncertainty.

To illustrate the ranges of values in individual IRPs, Figure 2 presents $\mathrm{CO}_{2}$ prices for 2025. The reference cases are shown along with ranges for the lowest and highest values considered. First, note that the reference case does not always correspond to the expected value of the carbon tax distribution, no matter how probabilities are assigned. ${ }^{6}$ Second, 8 of the 14 utilities (57 percent) consider a no-policy scenario to be a serious possibility. Finally, comparing these ranges to the estimated stringency of the Waxman-Markey bill (DOE/EIA, 2009) illustrates how the utilities in this sample expect that an implemented climate policy will have a lower price on carbon than the $\$ 47 / \mathrm{Mt}_{-} \mathrm{CO}_{2} \mathrm{e}$ reference value for Waxman-Markey in 2025. Only 5 of 14 utilities (36 percent) include this value in their potential range.

\footnotetext{
${ }^{5}$ The utilities selected for this analysis include: Avista, Idaho Power, Los Angeles Department of Water and Power (LADWP), NorthWestern, NV Energy, Pacific Gas and Electric (PG\&E), PacifiCorp, Portland General Electric (PGE), Public Service Company of Colorado (PSCo), Puget Sound Energy (PSE), San Diego Gas and Electric (SDG\&E), Seattle City Light, Southern California Edison (SCE), and Tri-State Generation and Transmission.

${ }^{6}$ Only two utilities (Avista and NorthWestern) attach probabilities to the price scenarios.
} 


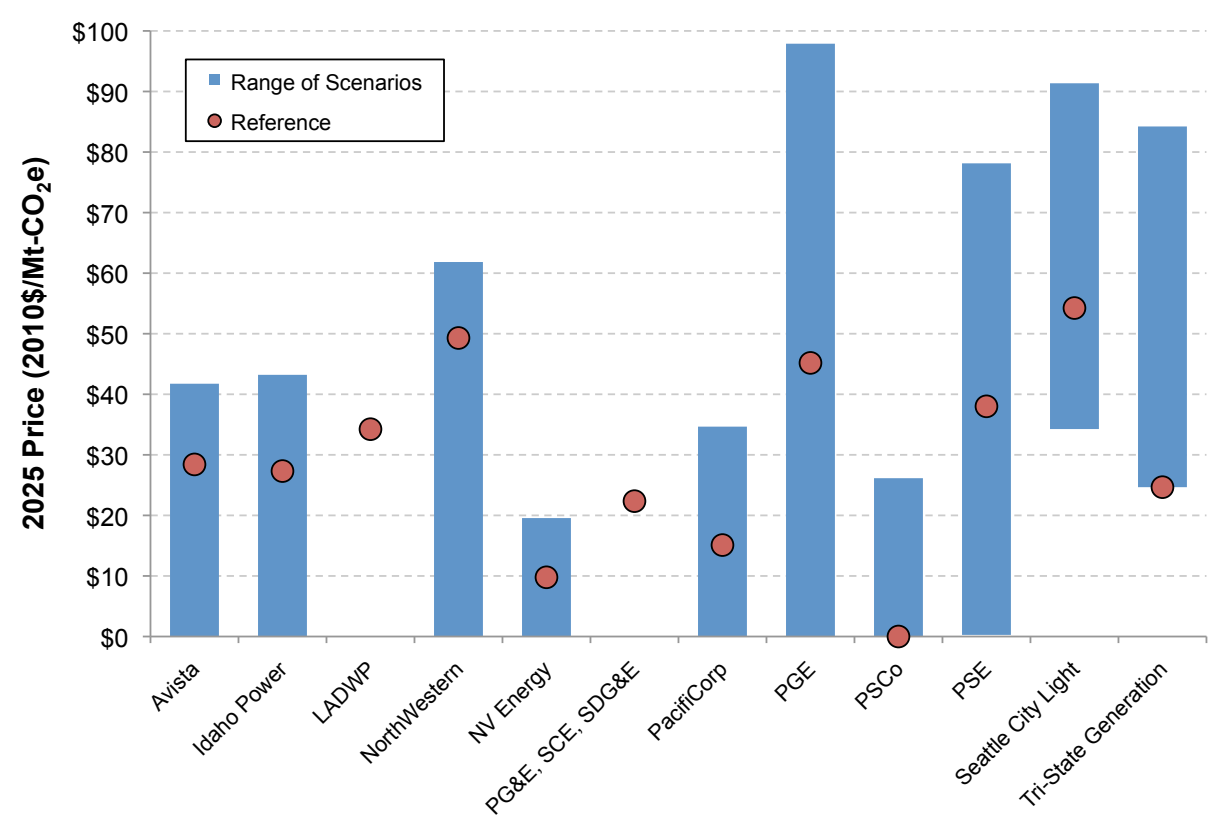

Figure 2: Carbon dioxide tax assumptions $\left(2010 \$ / \mathrm{Mt}_{-} \mathrm{CO}_{2} \mathrm{e}\right)$ in 2025 by utility.

The $\mathrm{CO}_{2}$ price trajectory data are used to create a distribution over potential 2025 prices. Each scenario is treated as an independent draw from this distribution, and a five-point probability mass function is used to represent this discrete random variable, which preserves the sample mean (approximately $\left.\$ 30 / \mathrm{Mt}-\mathrm{CO}_{2} \mathrm{e}\right)$ and variance.

\subsection{Natural Gas and Coal Prices}

Fuel prices are uncertain and fluctuate based on many complex factors. Uncertainty about the future of natural gas is also driven by increased domestic production of unconventional natural gas (Moniz et al., 2010). Although abundant gas resources suggest expanded use, uncertainty about long-run production costs, regulatory environmental, public acceptance, and environmental impacts make the extent of this growth unclear (McJeon et al., 2014; Huntington, 2013; IEA, 2012; DOE/EIA, 2011a; Coleman et al., 2011).

A vector autoregressive (VAR) model was created to estimate the probability distributions for future gas and coal prices for power generators. Using historical data for delivered fuel prices from the EIA's Annual Energy Review (DOE/EIA, 2011b) and forecast data from the Annual Energy Outlook 
(DOE/EIA, 2012), this work uses a two-step process to estimate the trend and variability for future fuel prices and then uses this VAR model to create density functions for annual growth rates for natural gas and coal prices. This model is based on the techniques developed by Zdybel (2013).

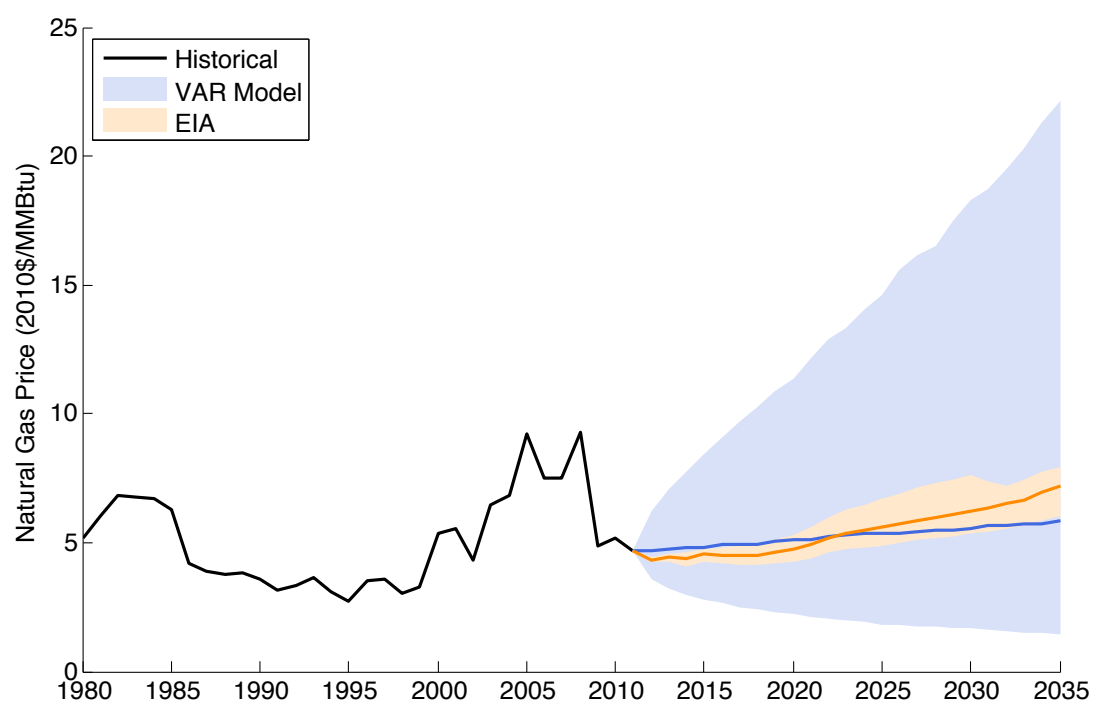

Figure 3: Historical and forecast delivered prices of natural gas for the electric power sector. The EIA cases represent the low price, reference, and high price scenarios (DOE/EIA, 2012). The VAR model results show the $10^{\text {th }}, 50^{\text {th }}$, and $90^{\text {th }}$ percentile values.

Figure 3 shows the uncertainty ranges for delivered natural gas prices for the VAR model results and the Annual Energy Outlook (DOE/EIA, 2012). The trend for gas prices closely mirrors the EIA forecast, with prices increasing only slightly over the coming decades. However, the results suggest that the uncertain range of prices may be much wider than the EIA projections, both on the lower and higher ends of the distribution. Modelers do not often quantify distributions over critical outputs or attach probabilities to possible scenarios, and there is evidence that, when analysts do quantify uncertainty, they tend to underestimate the range and probabilities associated with non-expected-value outcomes (Shlyakhtera et al., 1994). Although the EIA scenarios do not have associated probabilities, these results seem to support this finding and are consistent with the overconfidence effect.

Based on this analysis, the annual natural gas price growth rate can take values of $-5,0$, or 7 percent with probabilities of $0.30,0.34$, and 0.36 , respec- 
tively. Coal price growth rates can have possible realizations of -2 , 0 , or 2 percent with corresponding probabilities of $0.28,0.51$, and 0.21 , respectively.

\subsection{Methane Emissions from Gas Production}

In addition to future prices, another uncertain issue involving unconventional natural gas centers on the greenhouse gas impacts from its development. Research on life-cycle emissions from natural gas has been an active area of research over the past few years, which focuses primarily on upstream $\mathrm{CH}_{4}$ emissions. These studies exhibit a high degree of variation due to divergent assumptions and uncertainty in the underlying data (Brandt et al., 2014; Karion et al., 2013; Allen et al., 2013; Miller et al., 2013; Pétron et al., 2012; Burnham et al., 2012; Cathles et al., 2012; Howarth et al., 2012; EPA, 2011; Howarth et al., 2011; Hultman et al., 2011; Jiang et al., 2011; DOE/NETL, 2011). These problems are compounded by empirical data scarcities and the heterogeneity of sites and drilling practices.

This uncertainty is incorporated in the model as a random variable for emissions from shale gas production. Upstream $\mathrm{CO}_{2}$ and $\mathrm{CH}_{4}$ emissions also are included for coal and conventional natural gas production. The analysis assumes that upstream emissions from other greenhouse gases (apart from $\mathrm{CO}_{2}$ and $\mathrm{CH}_{4}$ ) are negligible. This analysis uses estimates of the global warming potential from Shindell et al. (2009) and a 100-year timescale. This work uses these values in a discrete three-point distribution with outcomes of $0.11,0.6$, and 1.18 grams of carbon per megajoule of fuel, which are interpreted as the $10^{\text {th }}, 50^{\text {th }}$, and $90^{\text {th }}$ percentiles. $^{7}$

\subsection{Other Uncertainties}

The model also includes four additional uncertain model parameters:

- Capital costs of nuclear and CCS: Technological uncertainties for nuclear and CCS-equipped coal and gas units are incorporated as distributions over investment costs. These distributions come from expert elicitations conducted at the Harvard Kennedy School (Anadon et al., 2011). The experts' elicited values are combined using Monte Carlo simulations with even weights assigned to all experts. For coal with CCS, using moment matching to create three-point discretizations

\footnotetext{
${ }^{7}$ Using the Extended Swanson-Megill approximation to assign probabilities provides a fairly robust approximation for a wide range of distributions (Keefer, 1994).
} 
yields potential outcomes of $\$ 2 \mathrm{k}, 4 \mathrm{k}$, and $6 \mathrm{k}(\$ / \mathrm{kW})$ with probabilities $0.39,0.44$, and 0.17, respectively. For Generation III/III+ nuclear reactors, the random variable can take the value of $\$ 2 \mathrm{k}, 4 \mathrm{k}$, and $7 \mathrm{k}$ $(\$ / \mathrm{kW})$ with probabilities $0.28,0.55$, and 0.17 , respectively.

- Public acceptance of $\mathrm{CO}_{2}$ storage: Although the technological, regulatory, and economic barriers to CCS development are considerable, public acceptance of CCS technologies and large-scale storage may be an equally daunting challenge, as public opposition has already been a factor in cancellations of proposed storage projects (Van Noorden, 2010). The public acceptance uncertainty for $\mathrm{CO}_{2}$ storage in the model uses probability estimates from a National Academies study (National Research Council, 2007), which accounts for public opposition based on risks from sequestration and siting. According to this study, the probability of normal storage is 0.66 , which implies a 0.34 probability that storage is prohibited.

- Natural gas combined cycle (NGCC) efficiency: In addition to uncertainties about the economic and environmental impacts of gas development, another relevant uncertainty is the performance of gas-turbinebased technologies. This analysis uses expert elicitation results from Bistline (2014a) to model uncertainty about the first-law efficiencies of these technologies. Using the Extended Swanson-Megill approximation, the three-point discretization of this random variable can take the value of 56,63 , and 72 percent with probabilities $0.3,0.4$, and 0.3 , respectively. 
Table 1: Uncertainties included in capacity planning model runs.

\begin{tabular}{lc}
\hline \hline \multicolumn{1}{c}{ Uncertainty } & Scenarios \\
\hline $\mathrm{CO}_{2}$ tax stringency & 5 \\
Natural gas price path & 3 \\
Coal price path & 3 \\
Upstream $\mathrm{CH}_{4}$ emissions & 3 \\
Coal with CCS capital costs & 3 \\
Nuclear capital costs & 3 \\
Public acceptance of $\mathrm{CO}_{2}$ storage & 2 \\
NGCC efficiency & 3 \\
\hline Total & 7,290 \\
\hline
\end{tabular}

Each of these random parameters is assumed to be independent, which gives rise to 7,290 scenarios (Table 1). The model uses a two-stage stochastic programming approach and is programmed in the General Algebraic Modeling Software (GAMS) environment using the DECIS system (Infanger, 1999). All uncertainties are assumed to resolve in 2025 .

\section{Results}

\subsection{Reference Results}

Table 2 lists objective function values for the wait-and-see $\left(z_{w s}\right)$, stochastic $\left(z^{*}\right)$, and expected-value $\left(z_{d}\right)$ solutions. The top rows list values when the uncertainties are considered individually, and the bottom row shows results for all eight uncertainties considered jointly.

The joint EVPI of $\$ 162$ billion is considerably larger than the VSS of $\$ 36$ billion, ${ }^{8}$ which indicates that resolving uncertainty is more valuable than simply accounting for it in modeling efforts. Additionally, the EVPI and VSS come primarily from two uncertainties: climate policy and natural gas prices. The highest values correspond to the natural gas price uncertainty, which underscores the significance of this factor in capacity-planning decisions.

\footnotetext{
${ }^{8}$ All values are expressed in US 2010 dollars with a discount rate of five percent.
} 
Table 2: Comparison of discounted system costs (billion \$) for the wait-and-see $\left(z_{w s}\right)$, stochastic $\left(z^{*}\right)$, and expected-value $\left(z_{d}\right)$ solutions when uncertainties are considered individually and jointly. The EVPI and VSS metrics are shown in the rightmost columns.

\begin{tabular}{l|ccc|rr}
\hline \hline Uncertainty & $z_{w s}$ & $z^{*}$ & $z_{d}$ & EVPI & VSS \\
\hline Stringency of abatement policy & 4,114 & 4,171 & 4,185 & 57 & 15 \\
Natural gas prices & 4,096 & 4,168 & 4,204 & 72 & 36 \\
Coal prices & 4,278 & 4,279 & 4,279 & 2 & 0 \\
Upstream $\mathrm{CH}_{4}$ emissions & 4,283 & 4,283 & 4,283 & 0 & 0 \\
Capital costs (coal with CCS) & 4,283 & 4,283 & 4,283 & 0 & 0 \\
Capital costs (nuclear) & 4,283 & 4,283 & 4,283 & 0 & 0 \\
Public acceptance of $\mathrm{CO}_{2}$ storage & 4,283 & 4,290 & 4,291 & 7 & 1 \\
NGCC efficiency & 4,283 & 4,283 & 4,283 & 0 & 0 \\
\hline Joint & 3,884 & 4,047 & 4,083 & 162 & 36 \\
\hline
\end{tabular}

To account for the relatively low VSS, it is instructive to compare firststage decisions under the stochastic and expected-value solutions. Table 3 lists capacity investments by generator type before uncertainty is resolved. ${ }^{9}$ The similarity between these two strategies accounts for the small VSS. Capital investments are concentrated primarily in wind and nuclear assets. This result suggests that these technologies are candidates for near-term hedges against a variety of uncertainties while allowing the power sector to keep pace with increasing demand and retirements of existing assets. These technologies are attractive investments due to their low life-cycle greenhouse gas emissions (which reduces exposure to the climate policy uncertainty) and to their low fuel price volatility (relative to alternatives like natural gas), which means that they are economical under a wider range of contingencies.

\footnotetext{
${ }^{9}$ Due to construction lead times, values in the table represent planned capacity but not necessarily completed additions by 2025 .
} 
Table 3: Cumulative capacity investments (GW) by 2025 under the stochastic and expected-value solutions.

\begin{tabular}{l|rr}
\hline \hline & Stochastic & Expected Value \\
\hline Biomass & 3 & 3 \\
Coal with CCS & 0 & 61 \\
Natural gas combined cycle & 0 & 0 \\
Nuclear & 289 & 287 \\
Wind & 139 & 139 \\
\hline Total & 431 & 490 \\
\hline
\end{tabular}

The largest difference between these strategies is the large investment in new capture-equipped coal generators under the expected-value solution. In part, the stochastic strategy avoids near-term CCS investments due to the possibility that these units would be mothballed or decommissioned if the climate policy is too stringent or if public opposition prevents cost-effective $\mathrm{CO}_{2}$ storage. The stochastic strategy delays capacity investments and instead relies on increased generation from existing, underutilized (i.e., lower capacity factor) gas units..$^{10}$

Apart from this stranded-cost effect, CCS additions are lower as a means to avoid irrevocably committing resources to assets that may displace investments in more lucrative capacity in later periods. Second-stage capital expenditures, made after more information is available, may profitably adjust deployment and dispatch to take advantage of unforeseen boons like unexpectedly low gas prices. In this instance, the stochastic strategy avoids investments in CCS-equipped units early on, which may entail sizable opportunity costs from foreclosed opportunities if built, and instead meets growing demand by utilizing existing gas units. In contrast, the mean carbon tax of $\$ 30 / \mathrm{Mt}-\mathrm{CO}_{2}$ lies in the permissible policy range where coal with CCS is lucrative, which means that the expected-value approach deploys this technology.

The profitability of delaying investment under uncertainty is effective in the US context for three reasons. First, the stochastic strategy can increase generation from underutilized gas capacity before uncertainty is revealed.

\footnotetext{
${ }^{10}$ Bistline (2014b) uses this model to explore policy-relevant insights about natural gas in the electric power sector.
} 
Second, retirements due to plants exceeding their anticipated economic lifetimes will not occur en masse for a couple decades. By that time, more information will likely be available about long-term policy trajectories, fuel prices, and technological characteristics. Finally, slower projections of electricity demand growth in the coming years will obviate the need for new investments right away.

Much like the VSS, the EVPI of $\$ 162$ billion is driven primarily by information for scenarios with less stringent carbon taxes and low gas prices. Information has value in lax climate policy scenarios, since it would be optimal to build fewer low-carbon units like wind and nuclear and instead wait to build cheaper fossil-based capacity, especially if gas prices are low.

A considerable amount of variance for the cost advantage of the stochastic strategy can be accounted for by two of the most important uncertainties (i.e., climate policy and natural gas prices), as illustrated in Figure 4. The decision not to build CCS capacity before uncertainties are resolved proves to be valuable in scenarios with low gas prices and lenient climate policies. In these scenarios, the first-best option is to build NGCC units during the second stage once information is known about modest carbon and low gas prices. However, for the expected-value approach, irreversible investments in coal with CCS during the first stage would provide less flexibility for taking advantage of these market opportunities.

One reason why explicitly accounting for uncertainty leads to decreased near-term investments in low-carbon technologies relates to abatement cost characteristics of the power sector. Total system costs (i.e., the objective function in the optimization problem) are concave in carbon taxes, with costs essentially plateauing around $\$ 20 / \mathrm{Mt}-\mathrm{CO}_{2}$. This general trait is consistent with a range of studies that find that a tax of $\$ 14-27 / \mathrm{Mt}-\mathrm{CO}_{2}$ would largely decarbonize new electricity generation (Weyant et al., 2006), which means that more stringent taxes would not substantially impact costs toward the second half of the modeling horizon. Consequently, if utilities plan for the mean tax $\left(\$ 30 / \mathrm{Mt}-\mathrm{CO}_{2}\right)$ and the most stringent case obtains, higher carbon taxes would not substantially impact second-stage costs. Thus, the only method of achieving cost savings is for utilities to avoid irreversible investments early on and hope that the low tax and gas price scenarios are realized so that second-stage investments are less costly. 


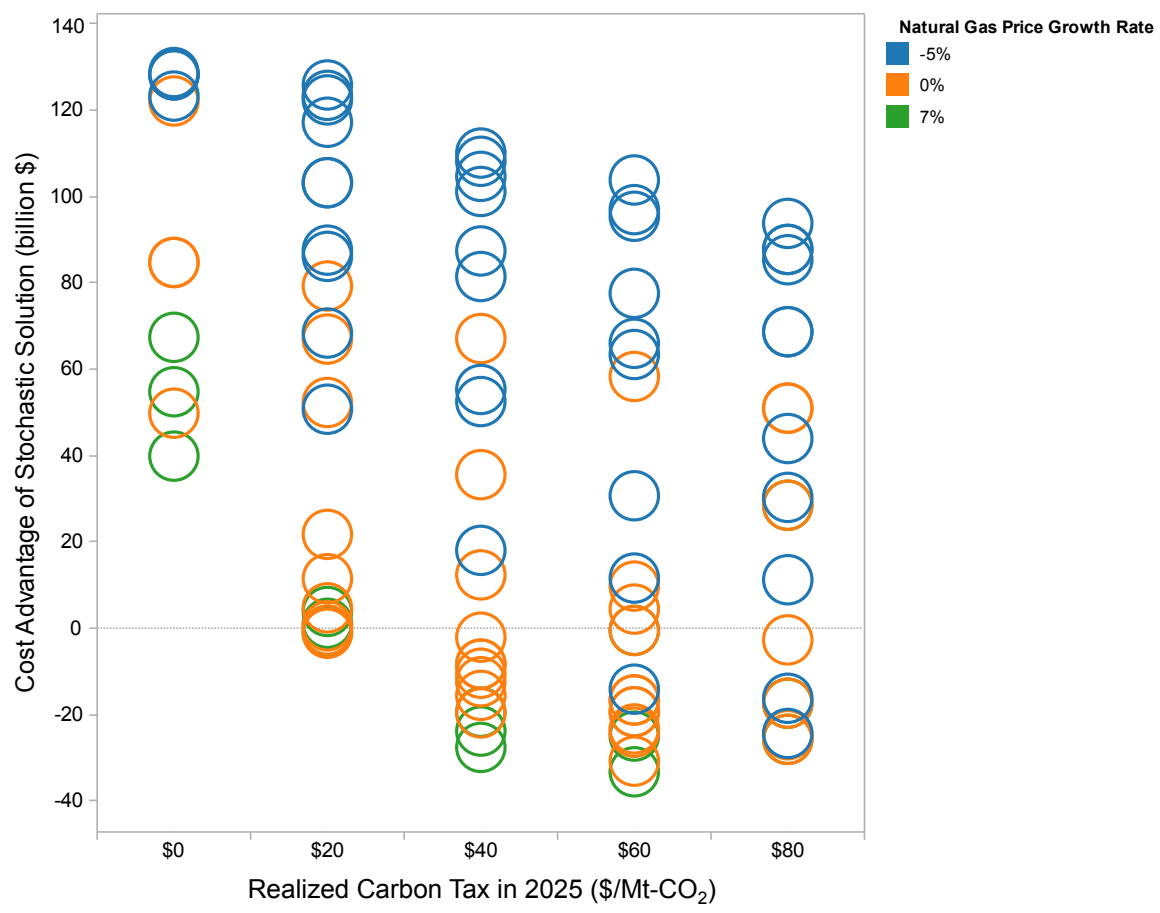

Figure 4: Cost advantage of the stochastic solution with different realized values of the climate policy uncertainty (horizontal axis) and natural gas price uncertainty (colors). Each circle represents one scenario of the 7,290 possible outcomes.

A parallel sensitivity considers the economic impact of limited CCS availability and suggests that the value of CCS readiness in the second stage is $\$ 13.8$ billion. This result illustrates that, although utilities have little nearterm incentive to build CCS-equipped capacity given climate policy uncertainty, CCS technologies may be important components of the long-term generation mix. More generally, the large losses under runs that exclude entire groups of technologies speak to the importance of maintaining a diverse portfolio of generation options that, if needed, are ready for deployment at reasonable cost and performance levels.

If learning effects are important for enhancing CCS readiness in future decades when greater abatement may be needed (IPCC, 2014), CCS deployment may require public-private partnerships for early pilot and demonstration projects as well as for R\&D for capture systems with lower parasitic losses. Rubin et al. (2007) show how historical experience curves for similar technologies like flue-gas desulfurization exhibited cost increases during 
initial stages of commercialization. These increases are primarily due to reliability and performance deficiencies in early designs, which are typically not incorporated in long-run learning rates. Thus, capital cost increases for early CCS units would be consistent with these observations and would be important factors in cost trajectories for CCS.

In another experiment, utilities and generators plan based on a "bestguess" assumption of no substantial climate policy instead of using the mean value. ${ }^{11}$ Utilities may view climate policy as an endogenous uncertainty with (partially) controllable outcomes, especially if climate risk is noisy and high evidentiary standards for control can delay action. Even if a carbon tax materializes, this scenario could represent the case where firms believe that there is a high likelihood that carbon-intensive units built before policy is enacted will be grandfathered into legislation.

If the VSS is computed assuming a no-policy baseline, the VSS increases to $\$ 61$ billion, which is much higher than the $\$ 36$ billion using the expectedvalue solution. In contrast to the baseline case, the no-policy solution builds no nuclear capacity and instead constructs $107 \mathrm{GW}$ of coal-fired units. These investments would entail substantial adjustment costs if emissions restrictions are later enacted or if gas prices are exceedingly low.

This experiment illustrates the importance of model assumptions about a decision-maker's expectations, why cancellations of planned coal additions observed around 2007 initially occurred (i.e., due to expectations that a carbon price would materialize in the near future), and why few coal additions have been proposed since (i.e., due to expectations that natural gas prices will remain low). This expected-value solution only performs well under a distribution that is compatible with the assumed no-policy prior, but the strategy is vulnerable when it encounters a world with a dramatically different distribution.

Overall, the results in this section suggest that uncertainty may provide incentives for strategic delay. Deferring (partially) irreversible investments can protect against downside losses while retaining the option value of waiting until more information is available about lucrative market opportunities. The

\footnotetext{
${ }^{11}$ This no-policy scenario can be interpreted in several ways: 1. Expectation of stalled international negotiations and/or disagreement at the federal level; 2. Anticipation of a discovery that climate change is not as threatening as expected; 3. Expectation of a low-risk geoengineering solution or cheap ambient air capture to decouple emissions from climate impacts.
} 
Australian carbon tax (repealed in 2014) illustrated this general approach of avoiding investments and utilizing existing assets to achieve compliance, since firms relied heavily on hydroelectric power from existing reservoirs given uncertain future support for the policy. Extending the model to include three decision stages could incorporate uncertainty about institutional credibility, which could heighten disincentives for early investment and increase regulatory costs (Bosetti and Victor, 2011). ${ }^{12}$ The VSS and EVPI values can help to prioritize future research efforts and to influence IRP requirements for scenario development and uncertainty analysis.

\subsection{Outdated Distributions}

The previous sections assume that utilities' probability distributions are based on the most up-to-date estimates of uncertainty; however, the decisionmaker's beliefs may depart from the best-available information for a variety of reasons. Overwhelmed by the number of interrelated factors that must be taken into consideration, decision-makers may adopt more lax tools for describing and dealing with risk in the planning process.

This section investigates the impact of using outdated distributions. Here, beliefs about fuel prices are based on the best-available information from 2007, but the outcomes are based on the most up-to-date distributions. In other words, first-stage decisions are made based on 2007 expectations for future coal and natural gas prices, but the realizations of random variables in the second stage come from the unexpected distributions discussed in Section 3.

Values for the outdated fuel prices come from the Energy Information Administration's 2007 Annual Energy Outlook (DOE/EIA, 2007). At that time, energy analysts were bullish on coal and only beginning to understand the long-term, transformative impacts of unconventional natural gas. According to a National Energy Technology Laboratory report (NETL, 2007), the resurgence of coal dominated the outlook for the electric power sector, as 145 GW of new coal capacity additions were planned by 2030. The 2007 Annual Energy Outlook uses a reference (mean) price of coal in 2030 of $\$ 1.87$

\footnotetext{
${ }^{12}$ The most significant barrier in moving from a two-stage to a multi-stage stochastic programming framework may be uncertainty quantification rather than the computational complexity of the resulting problem. Experimental literature suggests that laypeople and experts struggle with correlational structures (Morgan and Henrion, 1990), which would be required for conditional probability assessments in multi-stage programs.
} 
per MMBtu (in 2010 dollars) with an implicit annual growth rate of -0.9 percent, which is more optimistic than the current mean of $\$ 2$ (0 percent). In contrast, the 2007 Annual Energy Outlook reference gas price for 2030 is $\$ 7.07$ per MMBtu with a growth rate of 1.7 percent, which is higher than the current mean value of $\$ 6.10$ (1 percent).

Even minor differences between expectations of fuel price spreads lead to very different trajectories of capacity additions, generation, and emissions. Under the reference (2013) distributions with no climate policy, much of the retired coal capacity (and increasing demand) is replaced by highly efficient NGCC units so that 63 percent of generation by 2050 comes from natural gas. With expectations from 2007, new capacity investments come almost exclusively from supercritical pulverized-coal units so that 64 percent of generation comes from coal by 2050 .

Explicitly incorporating uncertainty is especially valuable given outdated 2007 expectations, as the VSS increases from $\$ 36$ billion to $\$ 80$ billion. Due to its bullish forecast about coal, the expected-value solution builds more coal with CCS in the first stage with 2007 priors (110 GW) compared with the most up-to-date values $(61 \mathrm{GW})$. As in Section 4.1, the VSS comes from avoiding investments in CCS to take advantage of cheap natural gas if available and to avoid stranding these assets in the event that the carbon tax is prohibitively high or low. This effect is more pronounced when utilities make first-stage decisions assuming that no climate policy will materialize, which has a VSS value of $\$ 243$ billion.

Figure 5 illustrates the risk associated with adopting stochastic and expectedvalue strategies under alternate assumptions about probability distributions. Plotting the cumulative distribution functions (CDFs) of the stochastic (black line) and expected-value (blue) strategies serves as an approximate visualization of the VSS, which is the integral between the CDFs of these two approaches. 


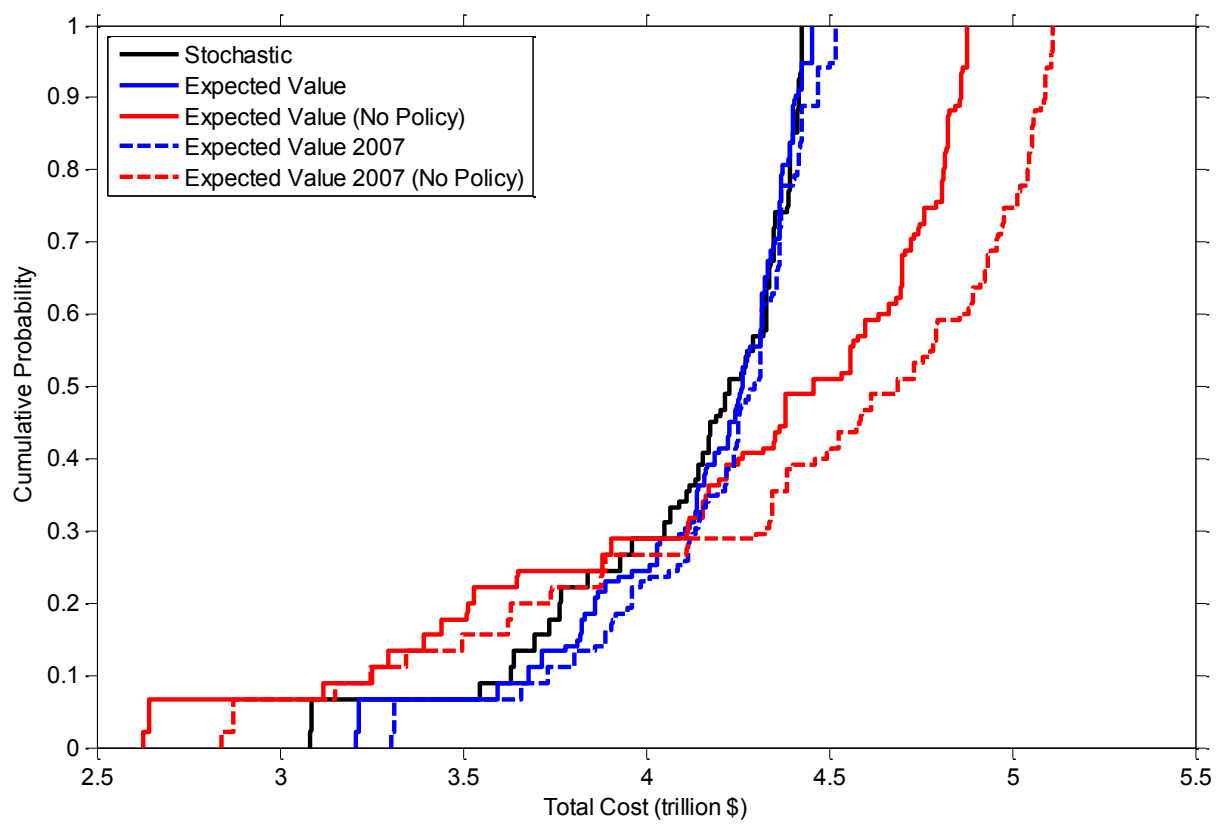

Figure 5: Cumulative distribution functions over discounted system costs (trillion $\$$ ) under the stochastic and expected-value solutions. The solid lines represent the reference distributions, and the dashed lines signify cases where 2007 distributions are assumed when first-stage decisions are made.

The stochastic solution not only protects against downside losses but also opens up the possibility of upside gains from volatility. For instance, when gas prices are lower than expected, delaying first-stage investments allows the stochastic solution to build more gas-fired capacity, which can take advantage of favorable market conditions. The antifragility (Taleb, 2012) of the stochastic approach provides a strong hedge against uncertainty, reduces risk, and presents simultaneous opportunities to adapt to evolving market conditions. Thus, the stochastic strategy attenuates the adverse effects of downside risk while retaining the option value of deferring irreversible commitments until more information is available about potentially lucrative opportunities. 


\section{Discussion}

\subsection{Optionality of Capital Investments}

Why is the value of information gathering (i.e., the expected value of perfect information) so much greater than the value of including uncertainty (i.e., the value of the stochastic solution) in electric sector planning? As shown in Figure 1, analyzing the EVPI and VSS involves comparing the expected costs of the expected-value, stochastic, and perfect information strategies.

The EVPI essentially measures the opportunity cost of delaying action. If access to early information equips utilities to make different decisions, the information has value. Otherwise, the EVPI is zero, and the decisionmaker can costlessly delay decisions until uncertainties are resolved. The high EVPI found in this analysis suggests that there is a limited availability and adequacy of the hedging options in the electric power sector. ${ }^{13}$

These conclusions underscore and reframe the notion that there are no silver bullet abatement technologies in the power sector. Evocations of this no-silver-bullet mantra typically emphasize the notable dearth of technologies that have the scale, wide applicability, cost characteristics, and technological readiness to reduce emissions in the context of meeting a deterministic emissions target. In this paper, the lack of silver bullet technologies is reflected in the conspicuous absence of near-term hedges that are robust for all uncertainties. Nuclear and low-cost wind are the only technologies with moderate deployment under the stochastic hedging strategy, though many large-scale nuclear builds may be costly in the next several years due to the increasing competitiveness of electricity markets, commodity price escalation, and utilities' small market capitalizations.

The VSS measures the degree of asymmetry in the decision-maker's loss function and the extent to which suboptimal decisions impact the objective function value. According to Morgan and Henrion (1990), the VSS is large (i.e., the expected-value solution is a bad approximation for the stochastic solution) when:

1. The optimization problem exhibits nonlinear or nonconvex behavior

2. Probability distributions on uncertain quantities are asymmetric (i.e., exhibit considerable skewness)

\footnotetext{
${ }^{13}$ This is another way of expressing the notion that there are no alternatives in the electricity generation choice set that are robust across all uncertainties.
} 
3. Dependence exists between random variables

4. Random variables have large supports

The VSS is small here due to many factors. Regarding point (1), the capacity planning problem is predominantly linear in nature, since cost nonlinearities are not included in the decision-maker's objective function given the framing discussed in Section 2.1. As described in Section 3, the distributions used in this analysis are largely symmetric, which means that (2) does not apply. Also, the distributions were created to avoid any explicit dependence between random variables (3) and to bypass large supports (4). Additionally, the VSS would likely be larger on a percentage basis if the capacity planning problem were examined from an individual firm's perspective instead of the aggregated utility and generator perspective examined here.

It is important to note that the EVPI and VSS are a small fraction of the objective function value. The EVPI of $\$ 162$ billion is 3.8 percent of the objective function value of $\$ 4.3$ trillion, and the VSS of $\$ 36$ billion is 0.8 percent. Figure 6 shows that 64 percent of the total costs come through dispatch and maintenance costs of capital (including fuel costs), whereas capital investments comprise just 24 percent. As a result, if first-stage decisions are suboptimal for the realized scenario ex post, total losses amount to the stranded costs of assets, which are only a small fraction of total costs across the time horizon. For instance, if the decision-maker builds too many NGCC units only to learn that gas prices are higher than expected, then the financial losses for a single power plant would only amount to perhaps $\$ 1$ billion of the $\$ 4,300$ billion objective function value. Recourse decisions that are made after information is revealed allow the system to adapt and to avoid incurring increased operating costs in perpetuity if initial decisions are wrong. 


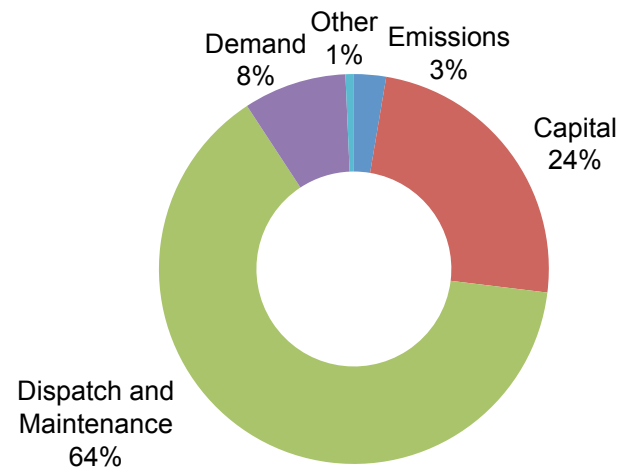

Figure 6: Decomposition of the objective function value of $\$ 4.3$ trillion total discounted costs.

This effect suggests that there are two relevant option values associated with power plant investments. The most commonly discussed and modeled value is the option of firms to invest in capital-intensive and essentially irreversible generators that can be delayed (Tuthill, 2008), which is analogous to a financial call option. This perpetual call option gives utilities the right, but not the obligation, to pay a specified amount (i.e., the strike price of the overnight capital cost) to receive an asset (i.e., a power plant) with uncertain future cash flows due to stochastic processes like prices of emissions permits and fuels. If and when the firm exercises this option to build the plant (i.e., when the asset's value sufficiently exceeds the exercise price and the option is "in the money"), the firm gives up the opportunity to wait for additional information about the future values of unknown quantities.

The above analysis suggests that the second relevant concept is that of a put option. After constructing a power plant, generators have the perpetual, costless, and quasi-reversible put option to generate electricity. They have the right, which they need not exercise, to pay the strike price (i.e., fuel costs) to receive an asset (i.e., revenue from generating and selling electricity). This perpetual put option allows generators to refuse to generate at a loss if the capital investment is later revealed to be incompatible with the realized scenario (e.g., if fuel prices or carbon taxes are too high).

The call option pertains to the initial capital investment decision, while the put option is relevant to the operational decision by firms once a unit has been constructed. Both options must be accounted for in the capacity planning problem. However, the choice of when and if to invest in the call option 
is essentially the capacity planning problem, which implicitly incorporates the downstream put-option (recourse) decision.

Ultimately, the resiliency that makes such options possible in electric sector planning comes through a variety of industry-specific sources - namely, the ability to react and to make decisions after new information becomes available, low opportunity costs associated with irreversible investments, and quick construction lead times relative to operating lifetimes.

\subsection{Policy Implications}

The results in Section 4 can help to inform regulatory design and timing decisions. The results illustrate how policy uncertainty may discourage precautionary capital investments in control equipment. Figure 5 shows that the most substantial cost risks and expected losses occur when utilities and generators make near-term decisions believing that the prospects of a low (or nonexistent) climate policy are increasingly likely. ${ }^{14}$

Given that this outcome would likely be socially suboptimal, a tiered approach to climate policy may be a more effective means of meeting many simultaneous goals. A tiered approach would offer simultaneous incentives for reducing emissions at federal, state, and local levels like carbon taxes, research and development $(\mathrm{R} \& \mathrm{D})$ investments, and technological standards. Although the policy redundancy may make any given policy less efficient, the potential co-benefits outside of reduced environmental damages may outweigh such deadweight losses (e.g., subsidized R\&D can remedy innovation externalities), especially if political economy constraints are binding.

A second policy implication is that sequential or staged approaches may be useful in reducing greenhouse gas emissions even before comprehensive legislation has been passed to put a price on carbon. The policy goal of reducing carbon emissions may be more politically feasible and may induce greater compliance if multiple policies are staged sequentially over time. Again, this precautionary approach to avoiding irreversible investments in carbon-intensive capital could be important if more-ambitious efforts to curb emissions through direct emissions-pricing policies prove to be politically infeasible in the future. Uncertainty about political processes, for instance,

\footnotetext{
${ }^{14}$ In addition to the interpretations suggested in Section 4.1, decision-makers also could be overly reliant on a single carbon policy scenario if their state public utility commission dictates the carbon prices used in resource planning, which may be lower than the realized carbon price (Barbose et al., 2008).
} 
may justify these complementary regulations.

The use of nested policy instruments with periodic reassessments is consistent with an adaptive approach to managing climate risk. The objective of adaptive management is to design policies, decision architectures, and institutions that encourage monitoring and active learning about systems and allow for flexibility, adjustment, and adaptation as new information becomes available. Sequential decision-making frameworks like the one used here are ideally suited to provide insights and decision support for adaptive management. For instance, the ozone regime established through the Montreal Protocol is a noteworthy example of an effective adaptive management framework and the only major international environmental effort to date to adopt such a system with repeated negotiations and dynamic ratchets that adjusted controls, refined its scope, and developed new institutions and mandates over time (Parson, 2003).

Adaptive management also improves upon some of the shortcomings of a contingent agreement approach to dynamic policies in environments of extreme complexity and uncertainty. Approaches based on contingent responses require the ex-ante specification and enumeration of all possible scenarios and optimal responses many years in advance, which neglect the potential for unexpected sources of information and the possibility that such information may generate greater uncertainty and novel questions.

\section{Conclusions}

This paper investigates the dynamics of capacity planning in the US electric power sector under a range of technological, economic, and policy-related uncertainties. The objective is to determine the sensitivity of near-term decisions to long-term uncertainties by developing stochastic strategies, which account for possible costs of midcourse corrections and hedge against a variety of upside and downside risks. The results suggest important insights about near-term decision-making under uncertainty and the modeling efforts that attempt to inform them.

Using a two-stage stochastic programming approach, model results suggest that the two most critical risks in the near-term planning process are natural gas prices and the stringency of climate policy. Stochastic strategies indicate some hedging from lower-cost wind and nuclear will occur but robustly demonstrate that delaying investment and waiting for more information can be optimal under certain conditions to avoid stranding capital- 
intensive assets. In particular, the stochastic approach will avoid near-term CCS investments due to the possibility that these assets would be decommissioned either if the climate policy too stringent or if public opposition prevents cost-effective $\mathrm{CO}_{2}$ storage. The stochastic strategy instead delays investment in new capacity and relies on increased generation from existing, underutilized (i.e., lower capacity factor) natural gas units. One interpretation of the results is that decision-makers have compelling incentives to pursue quasi-reversible alternatives that provide flexibility and avoid capitalintensive, long-lived investments. Section 5 explains these dampening effects of uncertainty in terms of the optionality of investments, leading to more general insights about uncertainty, learning, and irreversibility in the electric power sector.

It is important to note that the model results should not be interpreted as an argument for a do-nothing near-term strategy. As Manne (1996) emphasizes, "Delay should not be confused with inaction." The value of delaying investment to wait for more information applies only to coal with CCS capacity for the stochastic approach vis-à-vis the expected-value approach. Both approaches indicate that some near-term investments in wind and nuclear are optimal under a robust range of future scenarios. Additionally, the assumption that information will be received in 2025 hinges in part on the existence of sustained R\&D efforts in the interim.

Future work should prioritize nuclear power elicitations with careful debiasing to avoid overconfidence. The recommendations of nuclear as a nearterm hedging technology are based on comparatively optimistic cost elicitations and should be tempered by the recognition of the systematic historical overestimation of nuclear power deployment and underestimation of its associated costs (Grübler, 2010; Hultman et al., 2007; Koomey and Hultman, 2007; Cohen and Noll, 1991). Additionally, the model excludes potential sociopolitical concerns and uncertainties surrounding nuclear power. These factors (e.g., proliferation, waste disposal, safety) are inherently challenging to quantify, especially since risk perceptions are shaped by a combination of scientific risk assessments, cultural world-views, and psychological factors related to putative risk assessment (Kahan, 2012; Morgan et al., 2002; Douglas and Wildavsky, 1982). Incorporating these features would add additional risk to nuclear investments. Future work should also investigate how model representations of operational constraints and renewable integration costs may influence hedging decisions (Palmintier and Webster, 2014; Hirth, 2013).

The largest losses occur when decision-makers' beliefs depart from the 
best-available information either by using outdated distributions for fuel prices or by adopting optimistic beliefs about the ability to postpone compliance costs associated with a carbon policy. ${ }^{15}$ These results of misestimation stress the importance of using distributions that incorporate actual data instead of stylized, ad-hoc distributions. The VSS comes from the tendency to postpone investments in new generating capacity until more information is available or uncertainty is resolved. Such hedging policies not only protect against downside losses but also open up the possibility of upside gains from volatility (e.g., when natural gas prices are lower than expected).

These results suggest that a sequential approach to climate policy could incentivize preemptive and supererogatory abatement efforts until more comprehensive climate legislation is in place. These policies may be effective instruments to reduce cost risks for utilities, to incentivize the development of new technologies, to demonstrate the feasibility of emissions reductions by beginning with relatively low-cost restrictions, and to lower the probabilities of environmental hazards for society at large. The stochastic solution is especially valuable if decision-makers do not sufficiently account for the potential of climate constraints in future decades or if fuel price projections are outdated.

The results of this research also suggest that probability distributions from existing studies often exhibit overconfidence and do not reflect a full range of possible outcomes, as illustrated in forecasts for natural gas prices. Since the overconfidence effect narrows probability distributions, metrics like the EVPI and VSS are consequently biased downward (Hammitt and Shlyakhter, 1999). This pervasive bias suggests that existing analyses likely underestimate the value of gathering information about unknown quantities and of explicitly accounting for uncertainty in modeling efforts.

Given this context of overconfidence, decision-makers should expect (at least in the near term) to observe an increase in uncertainty over time (Maslin and Austin, 2013). As energy and environmental modeling communities continue to adopt formal methods of uncertainty quantification and analysis, the use of frameworks and metrics like those in this paper can reduce the deleterious effects of overconfidence and surprise. Important information is contained

\footnotetext{
${ }^{15}$ These results are especially relevant given the limitations of existing approaches for uncertainty analysis in utility resource planning, as described in Section 3 and in the literature (Wilkerson et al., 2014; Barbose et al., 2008).
} 
in non-mean-valued analyses, particularly in contentious research areas, and the results in Section 4 suggest that such uncertainty can materially influence near-term decisions. Future modeling efforts should carefully consider the impacts of potential surprises (even though such surprises, by their very nature, are elusive) and account for a broader range of uncertainties. The strategic selection of a wider array of sensitivities, robustness metrics, and probability distributions allows audiences to develop more complete insights from modeling exercises while also requiring more rigorous diagnostic experiments.

\section{Acknowledgements}

This research was supported by the William K. Bowes, Jr. Stanford Graduate Fellowship and by the Office of Science (BER), US Department of Energy. The paper benefited from the insightful comments and suggestions of John Weyant, Gerd Infanger, Jim Sweeney, Steve Comello, Hill Huntington, and two anonymous reviewers. The usual disclaimer applies. The views expressed in this paper do not necessarily reflect those of EPRI or its members. 


\section{Appendix A. Literature Review}

This section reviews the literature on energy modeling applications of stochastic programming with a focus on electric sector capacity planning. The purposive sample of papers discussed here focuses on the central articles only and is not an exhaustive survey of all relevant papers. Emphasis is placed on work that relates to the research methods and applications in this paper-namely, models with a bottom-up technological representation, national scale, and expected-value decision criterion.

Capacity planning models have a long history in the power sector, but uncertainty has only been included explicitly in recent decades. Long-range capacity planning for meeting a least-cost objective subject to operational constraints began in the 1950s alongside developments in mathematical programming (Massé and Gibrat, 1957). Dapkus and Bowe (1984) present one of the first applications of stochastic programming in this domain. The use of stochastic programming in energy models more generally is summarized in Wallace and Fleten (2003).

Tables A.4 and A.5 give a sense of the scope of stochastic programming research related to electric sector capacity planning with technologically detailed models. The tables include relevant details about the studies, including the model, scope, aggregation, and uncertainties. 


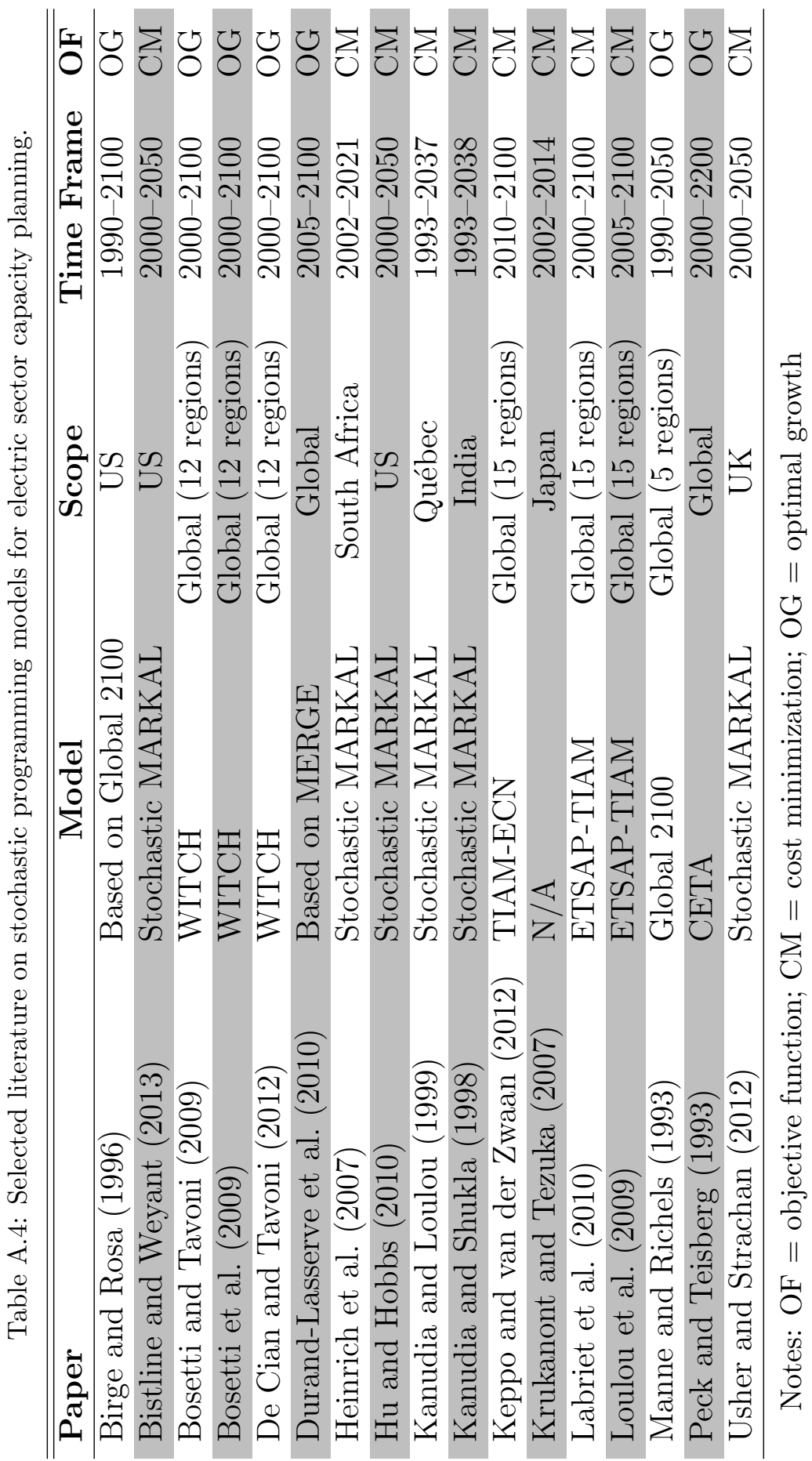




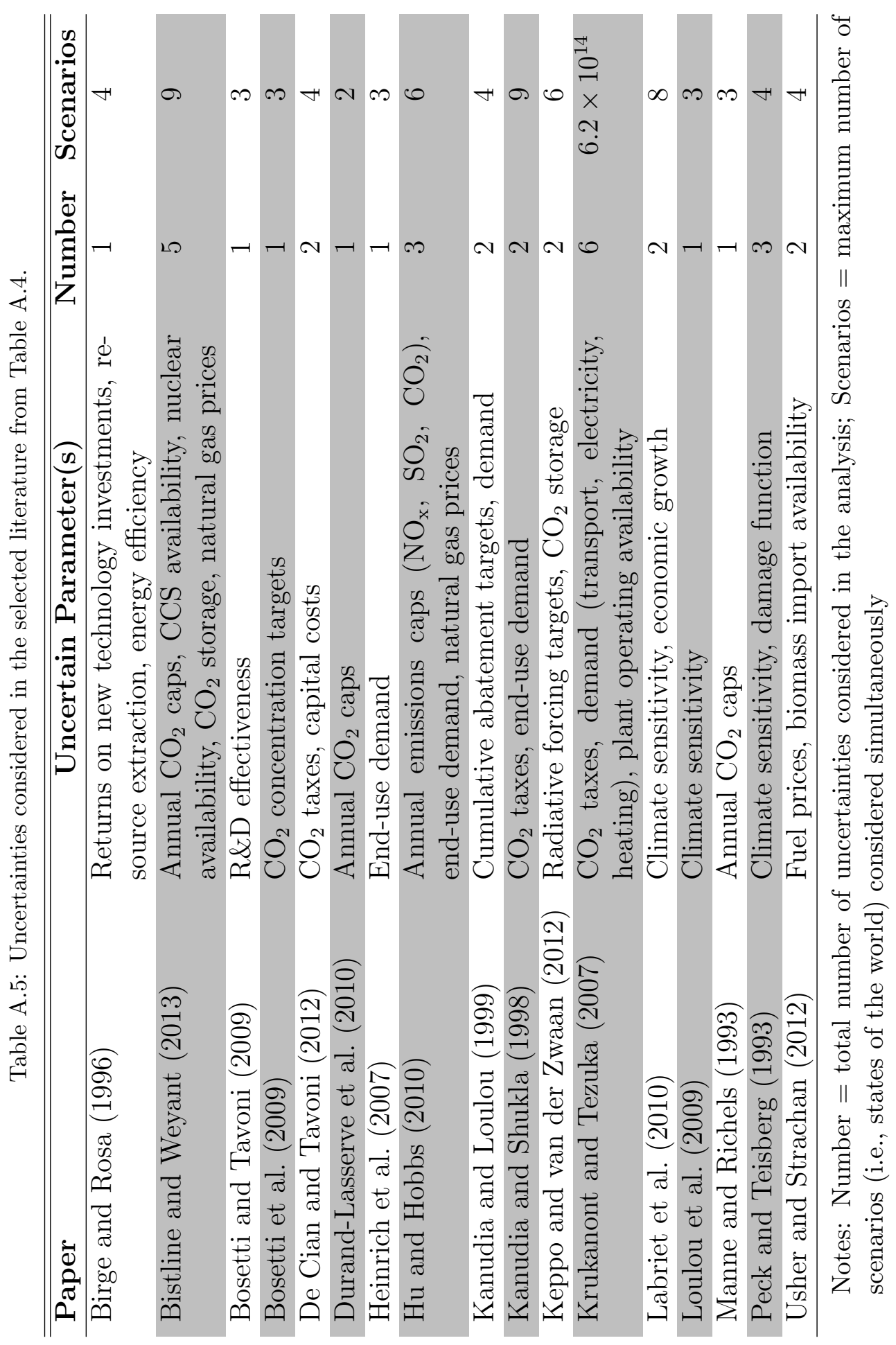




\section{Appendix A.1. Cost-Minimization Models}

Cost-minimization models find feasible solutions that minimize discounted energy system costs. Compared with their optimal-growth counterparts, cost-minimization models tend to have more detailed representations of energy technologies but do not capture macroeconomic interactions in as much detail.

The stochastic variant of the MARKet ALlocation (MARKAL) model is the most popular platform for the technology-detailed, policy-oriented studies in the literature. ${ }^{16}$ Kanudia and Loulou (1998) investigate how the uncertainties of economic growth and mitigation can affect energy system planning for Québec. ${ }^{17}$ A similar study by Kanudia and Shukla (1998) incorporates the same uncertainties for the Indian energy system and adds elastic demand. Heinrich et al. (2007) assess the impact of demand uncertainty on near-term decisions in a South African context using multiple objectives. $\mathrm{Hu}$ and Hobbs (2010) use stochastic MARKAL to calculate the EVPI, value of the stochastic solution (VSS), and value of policy coordination given uncertainties about multi-pollutant regulations in the United States (US), resource costs, and electricity demand. Usher and Strachan (2012) discuss near-term hedging strategies for long-term decarbonization pathways in the UK under uncertainties about fuel prices and biomass import availability. Bistline and Weyant (2013) demonstrate the utility of the stochastic programming framework and accompanying metrics using technological and policy-related uncertainties in the US electric sector as motivating examples. This paper draws attention to the limitations of stochastic MARKAL and stresses the need for new tools to better exploit the full range of benefits the stochastic programming approach can provide. Recent papers have used the stochastic TIMES model, which is an updated version of MARKAL, to examine uncertainties about the climate sensitivity parameter and economic development in multi-region, global settings (Labriet et al., 2010; Loulou et al., 2009).

The limitations of stochastic MARKAL are similar to other models employing stochastic programming in an energy policy context. Regardless of database size, stochastic MARKAL restricts the number of stages to two and the number of simultaneous scenarios to nine. ${ }^{18}$ The latter constraint

\footnotetext{
${ }^{16}$ An overview of the model can be found in $\mathrm{Hu}$ and Hobbs (2010).

${ }^{17}$ Loulou and Kanudia (1999) examine the same Québec system and compare results with a modified MARKAL model that uses a minimax-regret criterion.

${ }^{18}$ Although the TIMES model allows for a maximum of 64 states of the world, the
} 
considerably limits the number of uncertainties that can be considered simultaneously and their degree of detail. The limited types of parameters that can be treated as random variables in MARKAL is also restrictive. The formulation only allows parameters like environmental bounds and demand to be treated stochastically (Kanudia and Loulou, 1999), which eliminates from consideration classes of problems with uncertain objective function coefficients (e.g., capital costs). Additionally, with the exception of Kanudia and Shukla (1998), the stochastic MARKAL studies do not include priceresponsive demand, which can be limiting when examining the capacity planning problem under an uncertain climate policy.

Outside of the stochastic MARKAL framework, Krukanont and Tezuka (2007) analyze near-term investments and the EVPI in Japan under four uncertain policy regimes with uncertainties about $\mathrm{CO}_{2}$ taxes, demand, and plant operating availability. Although the analysis considers more scenarios than other studies, the model uses an extremely short time horizon of 12 years, which is shorter than the operating lifetimes of energy sector assets. Thus, the Krukanont and Tezuka (2007) study offers limited actionable insights about capacity planning decisions under uncertainty.

Finally, Keppo and van der Zwaan (2012) use the TIAM-ECN model to examine the impact of climate policy and $\mathrm{CO}_{2}$ storage potential. The results suggest that, if a stringent climate policy is included, this possible scenario dominates the near-term strategy and that the climate policy uncertainty plays a more important role in mitigation timing than storage. Like the MARKAL studies, Keppo and van der Zwaan (2012) only account for a limited range of possible uncertainties and do not focus on capacity deployment decisions and the associated policy implications.

\section{Appendix A.2. Optimal-Growth Models}

In addition to cost-minimization models, some papers use optimal economic growth models with utility-maximization objectives.

Manne and Richels (1993) are among the first to quantify the impact of uncertainty on energy decisions in the presence of climate change using a sequential decision-making approach. Using the Global 2100 model and an uncertain climate policy, their results show that the optimal near-term $\mathrm{CO}_{2}$

implementation is still based on directly solving the deterministic equivalent of the problem (Loulou and Lehtila, 2012), which severely limits the degree of model detail. 
emissions path lies between the extreme cases and that abatement levels are sensitive to the quality and timing of climate science research. Like the cost-minimization studies, Manne and Richels (1993) only consider a limited number of uncertainties and metrics for evaluation and instead focus on emissions trajectories.

Peck and Teisberg (1993) use the Carbon Emissions Trajectory Assessment (CETA) model to investigate uncertainty about the climate sensitivity and damage function parameters. They find that information about these uncertainties has a large value relative to existing research budgets and that resolving uncertainty about impacts is almost as critical as learning about the climate sensitivity parameter. The benefits of resolving uncertainty early are considerably larger when suboptimal abatement is undertaken in the near term, assuming that the climate policy could be adjusted once more information is available. Again, the study's restricted concentration on climaterelated uncertainty comes at the expense of insights related to technologyspecific deployment.

Birge (1995) considers how uncertainty on investment returns for energy technologies affects economic output, consumption, and emissions under annual $\mathrm{CO}_{2}$ restrictions. Using the VSS metric with a modified version of the Global 2100 model, the author finds that the optimal hedging strategy (i.e., instead of an expected-value strategy) increases economic output by approximately 1.4 percent annually and also recommends higher optimal $\mathrm{CO}_{2}$ taxes in early periods. Although the paper exemplifies how the VSS metric can be used for determining the impact of suboptimal planning on macroeconomic variables, Birge (1995) considers a very limited number of uncertainties and does not analyze how uncertainty affects technology-specific capacity installation and production decisions.

Bosetti and Tavoni (2009) analyze how innovation uncertainty may change climate policy recommendations using a stochastic variant of the World Induced Technical Change Hybrid (WITCH) model with a no-carbon backstop technology whose cost is a function of $R \& D$ spending. Results from an analytical model and WITCH conclude that accounting for uncertainty in R\&D effectiveness decreases climate policy costs and increases R\&D investments. However, the paper only considers a single cost-related uncertainty for a stylized technology under a fixed and certain climate stabilization policy (with an atmospheric $\mathrm{CO}_{2}$ concentration target).

Bosetti et al. (2009) use WITCH to investigate the cost of uncertainty for global stabilization targets and quantify the economic costs associated with 
delayed abatement. The paper suggests that short-term inaction is the leading determinant of welfare losses and increased compliance costs for stringent policies. These results indicate that a moderate near-term policy would be an effective hedging strategy until new information about the long-term severity of climate change arrives, which mirrors other conclusions in the literature (Yohe et al., 2004). The precautionary abatement under the hedging strategy is driven primarily by the stringent target of $450 \mathrm{ppmv}\left(\mathrm{CO}_{2}\right.$ only), which is explained by the convexity of marginal abatement costs. Overall, the paper's focus on the macroeconomic impacts of suboptimal strategies crowds out investigations of technology deployment decisions and does not account for the effect of other simultaneous uncertainties on utility-scale decisions.

De Cian and Tavoni (2012) also employ the stochastic programming variant of WITCH with uncertainties associated with $\mathrm{CO}_{2}$ taxes and capital costs for low-carbon technologies. Uncertainty about climate policy does not materially impact the first-stage abatement level or generation but primarily affects the portfolio of new capacity additions. The paper explores how different levels of uncertainty influence low-carbon capacity investments through mean-preserving spreads, which indicates that hedging in nuclear and renewables increases in $\mathrm{CO}_{2}$ price uncertainty (and CCS investments decrease). While the paper gives a more thorough portrait of how climate policy uncertainty influences investments in individual technologies, the work considers a limited number of potential policies, uncertainties, and metrics to evaluate the importance of uncertainty in decision-making.

Durand-Lasserve et al. (2010) illustrate how uncertainties about abatement targets (incorporated as annual $\mathrm{CO}_{2}$ emissions caps) may impact nearterm technology deployment decisions and $\mathrm{CO}_{2}$ prices using a modified version of the MERGE model. The results show how this uncertainty can impact near-term capacity decisions and energy-sector prices on regional and global scales. Ultimately, the focus of the paper is on the relationship between global policy uncertainty, $\mathrm{CO}_{2}$ prices, and emissions trajectories and not on capacity deployment decisions.

\section{Appendix A.3. Discussion and Contributions}

A few common conclusions emerge from the studies in Table A.4. First, sequential decision-making approaches offer novel insights that are not available through scenario analysis or Monte Carlo analysis. Stochastic programming models can recommend strategies that differ from deterministic ones 
where random variables are replaced by their expected values. ${ }^{19}$ Second, many studies point to the importance of climate policy uncertainties. Keppo and van der Zwaan (2012) conclude that uncertain climate targets dominate uncertainties about $\mathrm{CO}_{2}$ storage. When climate policy uncertainty is included, it seems to impact the portfolio of deployed technologies more than near-term abatement levels (De Cian and Tavoni, 2012).

Another takeaway is the low dimensionality of previous studies. As shown in Table A.5, models typically consider a limited number of uncertainties (with an average of 2.1 per study) and total scenarios (with an average of 4.7 per study). ${ }^{20}$ The large number of decision variables and associated computational burdens have limited previous analyses to simple scenario trees, which prevent more than a couple uncertainties from being investigated simultaneously and restricts the possibility that uncertainties can influence each other.

The limited number of scenarios capable of consideration is a consequence of the solving strategy. For stochastic linear programs with discrete distributions, the most common approach is to represent the problem as an equivalent deterministic linear program and then to solve directly, which is computationally costly for problems with many possible realizations. Two-stage stochastic linear programs can take advantage of their special block structures through a variety of decomposition procedures (Birge and Louveaux, 2011). When the number of possible realizations of random parameters is large, approximate solutions can be found through Monte Carlo sampling with variance reduction techniques (Infanger, 1999).

Table A.6 shows that many studies in the literature do not take advantage of metrics for assessing the relative importance of uncertainties. Metrics like the VSS and EVPI have important implications for decision-makers and modelers. However, the values in Table A.6 suggest that only 29 percent of studies in the sample provide calculations for the VSS and 53 percent for the EVPI.

\footnotetext{
${ }^{19}$ For instance, Usher and Strachan (2012) show that the stochastic hedging strategy is different from any deterministic (wait-and-see) solution and is structurally dissimilar from the average of the scenarios. Similar results are found in studies like Birge and Rosa (1996); Kanudia and Shukla (1998); Durand-Lasserve et al. (2010).

${ }^{20}$ The sample mean excludes the Krukanont and Tezuka (2007) paper, which considers notably more states of the world compared with other studies.
} 
Table A.6: Metrics used in the selected literature from Table A.4.

\begin{tabular}{lcc}
\hline \hline Paper & VSS & EVPI \\
\hline Birge and Rosa (1996) & $\bullet$ & $\bullet$ \\
Bistline and Weyant (2013) & $\bullet$ & $\bullet$ \\
Bosetti and Tavoni (2009) & & \\
Bosetti et al. (2009) & & \\
De Cian and Tavoni (2012) & & \\
Durand-Lasserve et al. (2010) & & \\
Heinrich et al. (2007) & $\bullet$ & \\
Hu and Hobbs (2010) & $\bullet$ & $\bullet$ \\
Kanudia and Loulou (1999) & $\bullet$ & $\bullet$ \\
Kanudia and Shukla (1998) & \\
Keppo and van der Zwaan (2012) & \\
Krukanont and Tezuka (2007) & \\
Labriet et al. (2010) & $\bullet$ \\
Loulou et al. (2009) & $\bullet$ \\
Manne and Richels (1993) & \\
Peck and Teisberg (1993) & $\bullet$ \\
Usher and Strachan (2012) & $\bullet$ \\
\hline
\end{tabular}

Notes: VSS $=$ value of the stochastic solution; EVPI

$=$ expected value of perfect information

Another shortcoming is the use of $a d$-hoc probability distributions instead of values based on rigorous modeling efforts. Many studies assume a uniform distribution over states of the world (i.e., invoking the Laplace criterion) to express an uninformative prior (Bosetti et al., 2009; Heinrich et al., 2007).

This paper investigates many uncertainties simultaneously using the DECIS system (Infanger, 1999), which is designed to use powerful decomposition techniques to solve stochastic programs with many scenarios. This modeling choice allows the research in Section 4 to incorporate a range of uncertainties with many thousands of scenarios. This work also applies a range of complementary metrics for quantifying the importance of uncertainty, which can indicate the value of reducing uncertainty and of using stochastic hedging approaches. These metrics provide a quantitative means of evaluating the significance of using sequential decision-making approaches for energy mod- 
eling. A third contribution of this work is to offer rigorous quantifications of distributions for technological, economic, and policy-related uncertainties instead of using ad-hoc probabilities, as discussed in Section 3.

\section{Appendix B. Detailed Capacity Planning Model Mathematics}

The model assumes that capacity installation and electricity production decisions are coordinated among utilities and generators. ${ }^{21}$ In the core deterministic model, planners determine the path of investment and capital stock that minimizes the sum of discounted energy system costs for all capacity blocks during all periods while satisfying power system constraints. ${ }^{22}$ The mathematical description of the model in this section uses the following sets and corresponding index notation:

\section{Sets and Indices}

$t \in \mathcal{T}$ time periods in the planning horizon

$i \in \mathcal{I} \quad$ generation technology types

$j \in \mathcal{J}$ load segments (i.e., subperiods in the load duration curve)

$s \in \mathcal{S}$ steps in the piecewise demand curve

The decision variables and parameters in the objective function are: ${ }^{23}$

\section{Decision Variables}

$x_{i}^{t} \quad$ new capacity investment of generation technology $i$ at time $t$ (GW)

$y_{i j}^{t} \quad$ dispatched capacity of type $i$ during load segment $j$ at time $t$ (GW)

$w_{i}^{t} \quad$ installed capacity of type $i$ available at time $t(\mathrm{GW})$

$u_{s}^{t} \quad$ reduced demand from step $s$ in the demand curve at time $t(\mathrm{GW})$

\footnotetext{
${ }^{21}$ The model data and code are available online.

${ }^{22}$ The model uses a discount rate of five percent unless otherwise noted to represent the market rate of return on capital.

${ }^{23}$ Decision variables for new capacity investments are continuous. The model does not include lumpy investments (i.e., large, discrete investments that are typically restricted to fixed sizes), which would require a mixed-integer formulation. The linear-programming formulation also does not account for economies and diseconomies of scale, which can be important in plant sizing decisions.
} 


\section{Parameters}

$\delta^{t} \quad$ discount factor at time $t$

$c_{i}^{t} \quad$ capital cost for type $i$ at time $t(\$ / \mathrm{kW})$

$\Delta_{i} \quad$ construction delay for type $i$ (years)

$f_{i}^{t} \quad$ total dispatch costs for type $i$ at time $t(\$ / \mathrm{kWh})$

$\tau_{j}^{t} \quad$ duration of segment $j$ at time $t$ (hours)

$g_{i}^{t} \quad$ maintenance costs for type $i$ at time $t(\$ / \mathrm{kW})$, including grid integration

$p_{s}^{t} \quad$ economic cost of reduced demand from step $s$ at time $t(\$ / \mathrm{kW})$

Given these variables and parameters, the linear cost-minimizing objective function (expressed in million $\$$ ) for the deterministic capacity planning problem is:

$$
\sum_{t} \delta^{t}\left(\sum_{i} c_{i}^{t} x_{i}^{t-\Delta_{i}}+\sum_{i} \sum_{j} f_{i}^{t} \tau_{j}^{t} y_{i j}^{t}+\sum_{i} g_{i}^{t} w_{i}^{t}+\sum_{s} p_{s}^{t} u_{s}^{t}\right)
$$

Thus, the four primary constituents of total costs are capital costs, dispatch costs, maintenance costs, and costs associated with reduced demand. ${ }^{24}$ Data for the model come from a variety of public sources, as shown in Table B.7.

Table B.7: Data sources for capacity planning model inputs.

\begin{tabular}{ll}
\hline \hline \multicolumn{1}{c}{ Data } & \multicolumn{1}{c}{ Source } \\
\hline Capital and O\&M costs & EIA (DOE/EIA, 2011d) \\
Existing capacity & Form EIA-860 (DOE/EIA, 2011c) \\
Availability/capacity factors & EPA National MARKAL Database 2010 \\
Fuel prices & EIA Annual Energy Outlook (DOE/EIA, 2011a) \\
Load & Based on Form EIA-860 (DOE/EIA, 2011c) \\
\hline
\end{tabular}

The model explicitly represents a broad range of electricity generation technologies, including various generations of nuclear power, solar and wind technologies, electricity from biomass, and multiple forms of fossil-based generating technologies with a variety of fuels and carbon capture options. Tech-

\footnotetext{
${ }^{24}$ Dispatch costs for preexisting and newly constructed generators are the sum of the variable operation and maintenance costs, fuel costs, and pollutant taxes. For carbon dioxide $\left(\mathrm{CO}_{2}\right)$ transport and storage costs, a piecewise supply curve for $\mathrm{CO}_{2}$ storage is incorporated into the model and calibrated using data from Dooley et al. (2004).
} 
nological cost and performance characteristics are exogenous inputs to the model, since the capacity planning formulation does not incorporate endogenous technical change. The model uses a vintaging structure to ensure that technological assumptions for a given time apply only to new deployments in that period and to create more realistic capital turnover and retirement dynamics.

The model incorporates a wind supply curve with increasing costs in deployed capacity. This curve accounts for the variable quality of wind resources in different regions of the country, heterogeneity in siting costs and availability, and transmission capacity constraints. ${ }^{25}$ Note that the model does not account for unit commitment constraints, which may overstate system flexibility and undervalue fast-ramping capacity like combustion turbines (Palmintier and Webster, 2014).

All model variants include the following constraints:

- Load balancing (market-clearing condition)

$$
\tau_{j}^{t}\left(\sum_{i} y_{i j}^{t}-\zeta_{j}^{t}\right)=\tau_{j}^{t}\left(d_{j}^{t}-\sum_{s} u_{s}^{t}\right)\left(1+\alpha^{t}\right) \quad \forall t, j
$$

where $\zeta_{j}^{t}$ represents net international exports during load segment $j$ at time $t(\mathrm{GW}), d_{j}^{t}$ is the reference demand level $(\mathrm{GW})$, and $\alpha^{t}$ is a factor that represents both transmission losses and a reserve buffer. This constraint ensures that demand is met in each subperiod and assumes that economical, grid-scale storage is not available.

- Dynamics of capital addition, turnover, and retirement

$$
w_{i}^{t}=w_{i}^{t-1}+x_{i}^{t-\Delta_{i}}-x_{i}^{t-\Delta_{i}-L_{i}} \quad \forall t, i
$$

where $L_{i}$ is the lifetime of type $i$.

- Production capacity bounds

$$
y_{i j}^{t} \leq a_{i j}^{t} w_{i}^{t} \quad \forall t, i, j
$$

\footnotetext{
${ }^{25}$ The curve is based on outputs from the Electric Power Research Institute's USREGEN model, which endogenously determines transmission builds using detailed wind resource data, an hourly dispatch model, and trade between regions through cross-border transmission (EPRI, 2014).
} 
where $a_{i j}^{t}$ represents the availability factor (i.e., ratio of the amount of time a generator can produce electricity in a given period to the period's duration) for type $i$ during segment $j$ at time $t$. This constraint mathematically formalizes the notion that unit dispatch cannot exceed the available capital stock.

- Demand reduction costs

$$
p_{s}^{t}=p_{0}^{t}\left(d_{j}^{t}\right)^{-\frac{1}{\varepsilon}}\left(d_{j}^{t}-\frac{s}{n} \bar{r} d_{j}^{t}\right)^{\frac{1}{\varepsilon}} \quad \forall t, s
$$

where $\bar{r}$ is the maximum demand reduction (as a percentage of the reference value), $n$ is the total number of steps in the stepwise linear representation of the aggregate demand curve, and $\varepsilon$ is the own-price elasticity of demand at the end-use level. ${ }^{26}$

- Investment constraints

$$
x_{i}^{t} \leq \bar{x}_{i}^{t} \quad \forall t, i
$$

where $\bar{x}_{i}^{t}$ represents the upper limit on new capacity investment of technology $i$ at time $t$. These upper bounds on expansion are based on current pipeline or other technological constraints and signify real-world frictions for new capacity installations. These expansion constraints take the form of annual limits on investment in specific technologies (e.g., carbon capture is assumed to be unavailable before 2020) but also of cumulative bounds for technologies like wind, which has resource and siting constraints.

- Non-negativity constraints

$$
x_{i}^{t}, y_{i j}^{t}, w_{i}^{t}, u_{s}^{t} \geq 0 \quad \forall t, i, j, s
$$

Since the electric power sector is characterized by long-lived and expensive investments, many technical and economic factors can contribute to the retirement of assets. Retirements occur in the model through three mechanisms. First, capacity may retire endogenously through economic drivers

\footnotetext{
${ }^{26}$ This stepwise linear formulation of price-sensitive demand represents only priceinduced energy conservation and efficiency, since autonomous conservation is implicitly included in the baseline load growth forecast. For a more thorough explanation of this approach, please refer to Kanudia and Shukla (1998).
} 
when maintenance costs for units exceed their anticipated economic benefits. Second, units that are online at the beginning of the time horizon are likely to be fully depreciated before the end. These exogenous lifetime constraints for residual capacity are incorporated through an upper bound on the percentage of units of a particular type that are online in a given period. Finally, the third mechanism for retirements occurs when new capacity reaches its operating lifetime during the time horizon of the model run, which also represents an exogenous constraint based on unit lifetimes.

\section{References}

Allen, D.T., Torres, V.M., Thomas, J., Sullivan, D.W., Harrison, M., Hendler, A., Herndon, S.C., Kolb, C.E., Fraser, M.P., Hill, A.D., Lamb, B.K., Miskimins, J., Sawyer, R.F., Seinfeld, J.H., 2013. Measurements of methane emissions at natural gas production sites in the United States. Proceedings of the National Academy of Sciences of the United States of America 110, 17768-17773.

Anadon, L.D., Bunn, M., Chan, G., Chan, M., Jones, C., Kempener, R., Lee, A., Logar, N., Narayanamurti, V., 2011. Transforming US Energy Innovation. Technical Report. Harvard Kennedy School, Belfer Center for Science and International Affairs.

Barbose, G., Wiser, R., Phadke, A., Goldman, C., 2008. Reading the Tea Leaves: How Utilities in the West Are Managing Carbon Regulatory Risk in Their Resource Plans. Technical Report LBNL-44E. Lawrence Berkeley National Laboratory: Environmental Energy Technologies Division.

Beale, E.M.L., 1955. On minimizing a convex function subject to linear inequalities. Journal of the Royal Statistical Society 17, 173-184.

Birge, J.R., 1982. The value of the stochastic solution in stochastic linear programs with fixed recourse. Mathematical Programming 24, 314-325.

Birge, J.R., 1995. Models and model value in stochastic programming. Annals of Operations Research 59, 1-18.

Birge, J.R., Louveaux, F., 2011. Introduction to Stochastic Programming. Springer, New York, NY. 
Birge, J.R., Rosa, C.H., 1996. Incorporating investment uncertainty into greenhouse policy models. The Energy Journal 17, 79-90.

Bistline, J.E., 2013. Essays on Uncertainty Analysis in Energy Modeling: Capacity Planning, R\&D Portfolio Management, and Fat-Tailed Uncertainty. Ph.D. thesis. Stanford University.

Bistline, J.E., 2014a. Energy technology expert elicitations: An application to natural gas turbine efficiencies. Technological Forecasting and Social Change 86, 177-187.

Bistline, J.E., 2014b. Natural gas, uncertainty, and climate policy in the US electric power sector. Energy Policy 74, 433-442.

Bistline, J.E., Weyant, J.P., 2013. Electric sector investments under technological and policy-related uncertainties: A stochastic programming approach. Climatic Change 121, 143-160.

Bosetti, V., Carraro, C., Sgobbi, A., Tavoni, M., 2009. Delayed action and uncertain stabilisation targets. How much will the delay cost? Climatic Change 96, 299-312.

Bosetti, V., Tavoni, M., 2009. Uncertain R\&D, backstop technology, and GHGs stabilization. Energy Economics 31, S18-S26.

Bosetti, V., Victor, D.G., 2011. Politics and economics of second-best regulation of greenhouse gases: The importance of regulatory credibility. The Energy Journal 32, 1-24.

Brandt, A., Heath, G.A., Kort, E.A., O’Sullivan, F., Pétron, G., Jordaan, S.M., Tans, P., Wilcox, J., Gopstein, A.M., Arendt, D., Wofsy, S., Brown, N.J., Bradley, R., Stucky, G.D., Eardley, D., Harriss, R., 2014. Methane leaks from North American natural gas systems. Science 343, 733-735.

Burnham, A., Han, J., Clark, C.E., Wang, M., Dunn, J.B., Palou-Rivera, I., 2012. Life-cycle greenhouse gas emissions of shale gas, natural gas, coal, and petroleum. Environmental Science and Technology 46, 619-627.

Cathles, L.M., Brown, L., Taam, M., 2012. A commentary on "The greenhouse-gas footprint of natural gas in shale formations" by R. W. Howarth, R. Santoro, and Anthony Ingraffea. Climatic Change 113, 525535. 
Cohen, L.R., Noll, R.G., 1991. The Technology Pork Barrel. The Brookings Institution, Washington, DC.

Coleman, J.L., Milici, R.C., Cook, T.A., Charpentier, R.R., Kirschbaum, M., Klett, T.R., Pollastro, R.M., Schenk, C.J., 2011. Assessment of Undiscovered Oil and Gas Resources of the Devonian Marcellus Shale of the Appalachian Basin Province, 2011. Technical Report US Geological Survey Fact Sheet 20113092. US Geological Survey.

Dantzig, G.B., 1955. Linear programming under uncertainty. Management Science 1, 197-206.

Dapkus, W.D., Bowe, T.R., 1984. Planning for new electric generation technologies: A stochastic dynamic programming approach. IEEE Transactions on Power Apparatus and Systems 103, 1447-1453.

De Cian, E., Tavoni, M., 2012. Mitigation portfolio and policy instruments when hedging against climate policy and technology uncertainty. Environmental Modeling and Assessment 17, 123-136.

DOE/EIA, 2007. Annual Energy Outlook 2007. Technical Report DOE/EIA0383(2007). US Department of Energy, Energy Information Administration.

DOE/EIA, 2009. Energy Market and Economic Impacts of H.R. 2454, the American Clean Energy and Security Act of 2009. Technical Report SROIAF/2009-05. US Department of Energy, Energy Information Administration.

DOE/EIA, 2011a. Annual Energy Outlook 2011. Technical Report DOE/EIA-0383(2011). US Department of Energy, Energy Information Administration.

DOE/EIA, 2011b. Annual Energy Review 2011. Technical Report DOE/EIA0384(2011). US Department of Energy, Energy Information Administration.

DOE/EIA, 2011c. Form EIA-860 Annual Electric Generator Report. URL: http://205.254.135.7s/cneaf/electricity/page/eia860.html. 
DOE/EIA, 2011d. Updated Capital Cost Estimates for Electricity Generation Plants. Technical Report. US Department of Energy, Energy Information Administration.

DOE/EIA, 2012. Annual Energy Outlook 2012. Technical Report DOE/EIA0383(2012). US Department of Energy, Energy Information Administration.

DOE/NETL, 2011. Life Cycle Greenhouse Gas Inventory of Natural Gas Extraction, Delivery, and Electricity Production. Technical Report DOE/NETL-2011/1522. US Department of Energy, National Energy Technology Laboratory.

Dooley, J.J., Dahowski, R.T., Davidson, C.L., Bachu, S., Gupta, N., Gale, J., 2004. $\mathrm{A} \mathrm{CO}_{2}$-storage supply curve for North America and its implications for the deployment of carbon dioxide capture and storage systems, in: Proceedings of the Seventh International Conference on Greenhouse Gas Control Technologies.

Douglas, M., Wildavsky, A.B., 1982. Risk and Culture: An Essay on the Selection of Technical and Environmental Dangers. University of California Press, Berkeley, CA.

Durand-Lasserve, O., Pierru, A., Smeers, Y., 2010. Uncertain long-run emissions targets, $\mathrm{CO}_{2}$ price, and global energy transition: A general equilibrium approach. Energy Policy 38, 5108-5122.

EPA, 2011. Inventory of US Greenhouse Gas Emissions and Sinks: 19902009. Technical Report EPA 430-R-11-005. US Environmental Protection Agency.

EPRI, 2014. Program on technology innovation: US-REGEN model documentation 2014. URL: http://www.epri.com/abstracts/Pages/ ProductAbstract . aspx?ProductId=000000003002004693.

Fischhoff, B., Slovic, P., Lichtenstein, S., 1977. Knowing with certainty: The appropriateness of extreme confidence. Journal of Experimental Psychology: Human Perception and Performance 3, 552-564.

Grübler, A., 2010. The costs of the French nuclear scale-up: A case of negative learning by doing. Energy Policy 38, 5174-5188. 
Hammitt, J.K., Shlyakhter, A.I., 1999. The expected value of information and the probability of surprise. Risk Analysis 19, 135-152.

Hannart, A., Ghil, M., Dufresne, J.L., 2013. Disconcerting learning on climate sensitivity and the uncertain future of uncertainty. Climatic Change 119, 585-601.

Heinrich, G., Howells, M., Basson, L., Petrie, J., 2007. Electricity supply industry modelling for multiple objectives under demand growth uncertainty. Energy 32, 2210-2229.

Hirth, L., 2013. The market value of variable renewables: The effect of solar wind power variability on their relative price. Energy Economics 38, 218-236.

Howarth, R.W., Santoro, R., Ingraffea, A., 2011. Methane and the greenhouse-gas footprint of natural gas from shale formations. Climatic Change 106, 679-690.

Howarth, R.W., Santoro, R., Ingraffea, A., 2012. Venting and leaking of methane from shale gas development: Responses to Cathles et al. Climatic Change 113, 537-549.

Hu, M.C., Hobbs, B.F., 2010. Analysis of multi-pollutant policies for the US power sector under technology and policy uncertainty using MARKAL. Energy 35, 5430-5442.

Hultman, N., Rebois, D., Scholten, M., Ramig, C., 2011. The greenhouse impact of unconventional gas for electricity generation. Environmental Research Letters 6.

Hultman, N.E., Koomey, J.G., Kammen, D.M., 2007. What history can teach us about the future costs of US nuclear power. Environmental Science and Technology 41, 2087-2094.

Huntington, H., 2013. EMF 26: Changing the Game?: Emissions and Market Implications of New Natural Gas Supplies. Technical Report EMF Report 26, Volume I. Energy Modeling Forum.

IEA, 2012. Golden Rules for a Golden Age of Gas. Technical Report. International Energy Agency. 
Infanger, G., 1994. Planning under Uncertainty: Solving Large-Scale Stochastic Linear Programs. Personal Transformation Press, Penryn, CA.

Infanger, G., 1999. GAMS/DECIS User's Guide.

IPCC, 2014. Working Group III Contribution to the Fifth Assessment Report of the Intergovernmental Panel on Climate Change. Technical Report. Intergovernmental Panel on Climate Change.

Jiang, M., Griffin, W.M., Hendrickson, C., Jaramillo, P., VanBriesen, J., Venkatesh, A., 2011. Life cycle greenhouse gas emissions of Marcellus shale gas. Environmental Research Letters 6.

Kahan, D.M., 2012. Cultural cognition as a conception of the cultural theory of risk, in: Roeser, S., Hillerbrand, R., Sandin, P., Peterson, M. (Eds.), Handbook of Risk Theory: Epistemology, Decision Theory, Ethics, and Social Implications of Risk. Springer, London, UK.

Kann, A., Weyant, J.P., 2000. Approaches to performing uncertainty analysis in large-scale energy/environmental policy models. Environmental Modeling and Assessment 5, 29-46.

Kanudia, A., Loulou, R., 1998. Robust responses to climate change via stochastic MARKAL: The case of Québec. European Journal of Operational Research 106, 15-30.

Kanudia, A., Loulou, R., 1999. Advanced bottom-up modelling for national and regional energy planning in response to climate change. International Journal of Environment and Pollution 12, 191-216.

Kanudia, A., Shukla, P.R., 1998. Modelling of uncertainties and price elastic demands in energy-environment planning for india. Omega 26, 409-423.

Karion, A., Sweeney, C., Pétron, G., Frost, G., Hardesty, R.M., Kofler, J., Miller, B.R., Newberger, T., Wolter, S., Banta, R., Brewer, A., Dlugokencky, E., Lang, P., Montzka, S.A., Schnell, R., Tans, P., Trainer, M., Zamora, R., Conley, S., 2013. Methane emissions estimate from airborne measurements over a western United States natural gas field. Geophysical Research Letters 40, 4393-4397. 
Keefer, D.L., 1994. Certainty equivalents for three-point discrete-distribution approximations. Management Science 40, 760-773.

Keppo, I., van der Zwaan, B., 2012. The impact of uncertainty in climat targets and $\mathrm{CO}_{2}$ storage availability on long-term emissions abatement. Environmental Modeling and Assessment 17, 177-191.

Koomey, J.G., Hultman, N.E., 2007. A reactor-level analysis of busbar costs for US nuclear plants, 1970-2005. Energy Policy 35, 5630-5642.

Krukanont, P., Tezuka, T., 2007. Implications of capacity expansion under uncertainty and value of information: The near-term energy planning of Japan. Energy 32, 1809-1824.

Labriet, M., Loulou, R., Kanudia, A., 2010. Modeling uncertainty in a large scale integrated energy-climate model, in: Filar, J.A., Haurie, A. (Eds.), Uncertainty and Environmental Decision Making: A Handbook of Research and Best Practice. Springer, New York, NY.

Loulou, R., Kanudia, A., 1999. Minimax regret strategies for greenhouse gas abatement: Methodology and application. Operations Research Letters 25, 219-230.

Loulou, R., Labriet, M., Kanudia, A., 2009. Deterministic and stochastic analysis of alternative climate targets under differentiated cooperation regimes. Energy Economics 31, S131-S143.

Loulou, R., Lehtila, A., 2012. Stochastic Programming and Tradeoff Analysis in TIMES. Technical Report. Energy Technology Systems Analysis Programme.

Madansky, A., 1960. Inequalities for stochastic linear programming problems. Management Science 6, 197-204.

Manne, A.S., 1996. Hedging Strategies for Global Carbon Dioxide Abatement: A Summary of Poll Results. Technical Report WP 14.2. Energy Modeling Forum 14 Subgroup (Analysis for Decisions under Uncertainty).

Manne, A.S., Richels, R.G., 1993. Buying Greenhouse Insurance: The Economic Costs of $\mathrm{CO}_{2}$ Emission Limits. The MIT Press, Cambridge, MA. 
Maslin, M., Austin, P., 2013. Uncertainty: Climate models at their limit? Nature 486, 183-184.

Massé, P., Gibrat, R., 1957. Application of linear programming to investments in the electric power industry. Management Science 3, 149-166.

McJeon, H., Edmonds, J., Bauer, N., Clarke, L., Fisher, B., Flannery, B.P., Hilaire, J., Krey, V., Marangoni, G., Mi, R., Riahi, K., Rogner, H., Tavoni, M., 2014. Limited impact on decadal-scale climate change from increased use of natural gas. Nature 514, 482-485.

Miller, S.M., Wofsy, S.C., Michalak, A.M., Kort, E.A., Andrews, A.E., Biraud, S.C., Dlugokenckyd, E.J., Eluszkiewiczf, J., Fischer, M.L., JanssensMaenhouth, G., Miller, B.R., Miller, J.B., Montzka, S.A., Nehrkornf, T., Sweeney, C., 2013. Anthropogenic emissions of methane in the United States. Proceedings of the National Academy of Sciences of the United States of America 110, 20018-20022.

Moniz, E.J., Jacoby, H.D., Meggs, A.J.M., 2010. The Future of National Gas: Interim Report. Technical Report. Massachusetts Institute of Technology.

Morgan, M.G., Fischhoff, B., Bostrom, A., Atman, C.J., 2002. Risk Communication: A Mental Models Approach. Cambridge University Press, Cambridge, UK.

Morgan, M.G., Henrion, M., 1990. Uncertainty: A Guide to Dealing with Uncertainty in Quantitative Risk and Policy Analysis. Cambridge University Press, Cambridge, UK.

Morgan, M.G., Keith, D.W., 1995. Subjective judgments by climate experts. Environmental Science and Technology 29, 468A-476A.

National Research Council, 2007. Prospective Evaluation of Applied Energy Research and Development at DOE (Phase Two). Technical Report. The National Academies Press.

NETL, 2007. Tracking New Coal-Fired Power Plants: Coal's Resurgence in Electric Power Generation. Technical Report. US Department of Energy, National Energy Technology Laboratory. 
Palmintier, B., Webster, M., 2014. Heterogeneous unit clustering for efficient operational flexibility modeling. IEEE Transactions in Power Systems .

Parson, E.A., 2003. Protecting the Ozone Layer: Science and Strategy. Oxford University Press, Oxford, UK.

Peck, S.C., Teisberg, T.J., 1993. Global warming uncertainties and the value of information: An analysis using CETA. Resource and Energy Economics $15,71-97$.

Pétron, G., Frost, G., Miller, B.R., Hirsch, A.I., Montzka, S.A., Karion, A., Trainer, M.K., Sweeney, C., Andrews, A.E., Miller, L., Kofler, J., Bar-Ilan, A., Dlugokencky, E.J., Patrick, L., Moore, C.T., Ryerson, T.B., Siso, C., Kolodzey, W., Lang, P.M., Conway, T.J., Novelli, P., Masarie, K., Hall, B., Guenther, D., Kitzis, D., Miller, J., Welsh, D., Wolfe, D., Neff, W., Tans, P., 2012. Hydrocarbon emissions characterization in the Colorado Front Range: A pilot study. Journal of Geophysical Research 117.

Rubin, E.S., Yeh, S., Antes, M., Berkenpas, M., Davison, J., 2007. Use of experience curves to estimate the future cost of power plants with $\mathrm{CO}_{2}$ capture. International Journal of Greenhouse Gas Control 1, 188-197.

Shindell, D.T., Faluvegi, G., Kock, D.M., Schmidt, G.A., Unger, N., Bauer, S.E., 2009. Improved attribution of climate forcing to emissions. Science $326,716-718$.

Shlyakhtera, A.I., Kammen, D.M., Broido, C.L., Wilson, R., 1994. Quantifying the credibility of energy projections from trends in past data: The US energy sector. Energy Policy 22, 119-130.

Taleb, N.N., 2012. Antifragile: Things That Gain from Disorder. Random House, New York, NY.

Tuthill, L., 2008. Investment in Electricity Generation under Emissions Price Uncertainty: The Plant-Type Decision. Technical Report EV 39. Oxford Institute for Energy Studies.

Usher, W., Strachan, N., 2012. Critical mid-term uncertainties in long-term decarbonisation pathways. Energy Policy 41, 433-444. 
Van Noorden, R., 2010. Carbon sequestration: Buried trouble. Nature 463, 871-873.

Wallace, S.W., Fleten, S.E., 2003. Stochastic programming models in energy. Handbooks in Operations Research and Management Science 10, 637-677.

Weyant, J.P., de la Chesnaye, F.C., Blanford, G.J., 2006. Overview of EMF21: Multigas mitigation and climate policy. The Energy Journal , 1-32.

Wilkerson, J., Larsen, P., Barbose, G., 2014. Survey of Western US electric utility resource plans. Energy Policy 66, 90-103.

Yohe, G., Andronova, N., Schlesinger, M., 2004. To hedge or not against an uncertain climate future? Science 306, 416-417.

Zdybel, R.M., 2013. R\&D Portfolio Analysis of Low Carbon Energy Technologies to Reduce Climate Change Mitigation Costs. Ph.D. thesis. University of Massachusetts Amherst. 